\title{
"Chascones". Dictadura, movimiento estudiantil y militancia en el ala izquierda de la Juventud Demócrata Cristiana JDC, 1973 - 1989
}

\author{
"Chascones". Dictatorship, students' movement and affiliation on the left wing \\ of the christian democratic youth, 1973-1989
}

Víctor Muñoz Tamayo*

\begin{abstract}
Resumen: Este artículo ahonda en la historia de la Juventud Demócrata Cristiana JDC durante la dictadura de Pinochet, focalizando en la corriente partidista que se denominó "los chascones". Se expone el nacimiento y desarrollo de esta corriente, sus vínculos con el movimiento estudiantil y de derechos humanos, con los otros partidos opositores, con la tendencia adversaria de "los guatones" y con la DC adulta. Se sostiene que "los chascones" basaron su identidad tendencial, fundamentalmente, en un posicionamiento político estratégico para enfrentar la dictadura, y que terminada esta última, no mantuvieron elementos de facción visible, organizada y con fuerte identidad. Para este trabajo se realizaron entrevistas a 10 exdirigentes JDC, se revisó documentación partidaria, testimonial, prensa y bibliografía especializada.
\end{abstract}

Palabras claves: Juventud Demócrata Cristiana, Partido Demócrata Cristiano, "Chascones", Dictadura, Movimiento Estudiantil.

\begin{abstract}
This article delves into the history of the JDC Christian Democratic Youth during Pinochet's dictatorship, focusing on the partisan group called "los chascones". The birth and development of this group is exposed, its links with the student movement and human rights, with other opposition parties, with the adversary tendency of "Los Guatones" and the adult groups within the DC party. The article argues that "Los chascones" based their tendency identity, fundamentally on a strategic political position to face the dictatorship, and when this dictatorship ended, they did not mantain elements of a visible, organized and strong identity faction. For this paper, interviews were conducted with 10 former JDC leaders and documentation, testimonial, press and specialized bibliography were included.
\end{abstract}

\footnotetext{
* Chileno. Historiador, Doctor en Estudios Latinoamericanos (UNAM). Investigador del Centro de Investigaciones en Ciencias Sociales y Juventud de la Universidad Católica Silva Henríquez UCSH. Este trabajo se enmarca en el proyecto FONDECYT Iniciación número 11140307, tres años de duración y titulado: "Generaciones, cultura militante y faccionalismo en los partidos Socialista y Demócrata Cristiano de Chile. Cambios contemporáneos en las nociones de "la política", "el partido" y su vinculación con la sociedad. vmunozt@ucsh.cl.
} 
Key words: Christian Democratic Youth, Christian democratic party, "Chascones", Dictatorship, Students movement.

Recibido: 29 agosto 2019 Aceptado: 30 octubre 2019

\section{Introducción}

El presente texto ahonda en la historia la Democracia Cristiana durante la dictadura de Pinochet, y focaliza en la corriente partidista ${ }^{1}$ que se denominó coloquialmente como "los chascones“. Esta corriente se originó en oposición a las definiciones de la directiva conducida por Patricio Aylwin entre 1973 y 1976, y en pugna con la corriente oficialista DC conocida como "los guatones". Si bien "chascones" y "guatones" referían a un debate y un accionar presente en el partido adulto y en la juventud, es en esta última en donde emerge como distinción identitaria con notable grado de organicidad y visibilidad, y es desde ahí que se proyecta como nomenclatura a instalarse en la cultura militante demócrata cristiana durante la dictadura. Considerando lo anterior, el presente texto focaliza en el desarrollo de la tendencia chascona al interior de la Juventud Demócrata Cristiana JDC.

Se expone, por tanto, un seguimiento a los chascones de la JDC durante toda la dictadura, sus vínculos con movimientos y organizaciones sociales (particularmente, el movimiento estudiantil universitario y el activismo juvenil en derechos humanos), sus relaciones con los otros partidos opositores y con la DC adulta. A partir de esa revisión histórica, se sostiene que "los chascones" basaron su identidad tendencial en un posicionamiento político estratégico para enfrentar al régimen más que en un proyecto de sociedad específico a proyectar en democracia, cuestión que explica, en parte, por qué no persistieron como corriente visible, organizada y con relato identitario durante la posdictadura.

\section{Quiebres y definiciones de la JDC antes del golpe}

La Democracia Cristiana llegó al poder en 1964 como un partido ideológico que había optado por no establecer alianzas con otros partidos para llegar al gobierno. ${ }^{2}$ En tales circunstancias, la DC estableció que su mayor cercanía o disponibilidad a establecer

\footnotetext{
${ }^{1}$ En las ciencias sociales no existe un consenso sobre categorías como "corrientes", "tendencias", "facciones" y "fracciones". El cientista político Giovanni Sartori, reconociendo esta situación, llama "fracción" al fenómeno general de la subdivisión partidaria, distinguiendo en ese nivel entre las "tendencias" que sugieren conjuntos establecidos de actitudes que expresan diferenciaciones poco visibles, y las "facciones" que serían grupos específicos y con alta visibilidad dentro de un partido. En el presente texto abordamos la evolución de aspectos como la organicidad, visibilidad e identidad del subgrupo de los chascones de la JDC entre 1973 y 1989. Para ello, hemos preferido usar los términos "corrientes" y "tendencias" en tanto sinónimos y como conceptos genéricos referidos al fenómeno de los subgrupos partidarios. Ver: Giovanni Sartori, Partidos y sistemas de partidos, Madrid, Alianza, 2005.

2 Ver: George Grayson, El Partido demócrata Cristiano Chileno, Buenos Aires, Francisco de Aguirre, 1968.
} 
acuerdos con la derecha o la izquierda marxista, no se resolvería como lo había hecho pendularmente el Partido Radical (gobernando con unos u otros), sino manteniendo la cohesión en torno a su propio programa. Esta tesis del "camino propio" no impidió que la DC permaneciera tensionada por cuestiones que siguieron teniendo correspondencia con los puntos de referencia del espectro político, es decir, se enfrentaron posiciones inclinadas hacia la derecha o la izquierda, que priorizaban el relato revolucionario o el estabilizador, o, dicho de otro modo, que se sentían más identificadas por un antiderechismo o un antimarxismo.

Uno de los puntos centrales de estas disyuntivas se dio con relación a los contenidos doctrinarios del partido a ser aplicados desde el proyecto gubernamental. De tal modo, el PDC estuvo atravesado por una diferenciación entre, por un lado, quienes ponían acento en que el proyecto nacional a impulsar debía ser reformista y desarrollista en el sentido de modernizar y humanizar un capitalismo que se consideraba atrasado; y quienes, por otro lado, enfatizaban en el sello revolucionario de la DC, promoviendo un horizonte alternativo al capitalismo y al socialismo de modelo soviético, con carácter comunitario, plural y democrático, y que algunas corrientes definieron como "comunitarismo" y otras como "socialismo comunitario“. En 1966, los acuerdos del Segundo Congreso Nacional de la DC vincularon la "revolución en libertad" con una "vía no capitalista de desarrollo", cuestión que llevó al Consejo Nacional del partido a constituir una comisión político - técnica especial para estudiar en detalle los elementos de tal vía y proponer medidas para su impulso durante el gobierno de Frei. ${ }^{3}$ El documento que produjo aquella comisión fue aprobado en general por la Junta Nacional de la DC, pero desató oposición en sectores que consideraron que la propuesta restringía el rol de la iniciativa privada en la economía. ${ }^{4}$ De tal modo, las "dos almas" demócrata cristianas que antes de 1966 coexistían, e incluso se imbricaban, sin generar mayores tensiones ni corrientes nítidas, hacia 1967 tendieron a distinguirse y friccionarse hasta articular grupos definidos y en oposición. ${ }^{5}$

El énfasis reformista desarrollista o revolucionario alternativo del proyecto del PDC era evaluado según la propia acción gubernamental, y se fueron configurando corrientes que se diferenciaban en su valoración en torno al gobierno y sus reformas, juzgando a estas como adecuadas o insuficientes en la forma y/o sus tiempos de implementación. Fue así como, de acuerdo a una mayor o menor cercanía con la dirección de Frei y sus énfasis doctrinarios, se distinguieron tres tendencias partidarias: el grupo denominado "Rebelde" que exigía cambios más radicales hacia un desarrollo no capitalista entendido como socialismo comunitario, una línea "Tercerista" que mantenía similares posiciones de inclinación hacia la izquierda pero desde un lugar menos rupturista con el partido, y el

\footnotetext{
3 Ver: “Acuerdo del Consejo Nacional del Partido Demócrata Cristiano para la constitución de una Comisión Política - Técnica para estudiar y proponer una "vía no capitalista de desarrollo", Santiago, 6 de abril de 1967, Archivo Patricio Aylwin. Y: Jacques Chonchol, Tomás Reyes, Luis Maira, Vicente Sota, Julio Silva, Carlos Massad, Pedro Felipe Ramírez, Documento de trabajo para la Junta Nacional del PDC "Proposiciones para una acción política en el período 1967 - 70 de una vía no capitalista de desarrollo“, Santiago, Julio de 1967, Archivo Patricio Aylwin.

4 Ver críticas al informe en: "Carta de Patricio Aylwin a los miembros de la Junta Nacional del Partido Demócrata Cristiano, con observaciones al informe político técnico de una vía no capitalista de desarrollo”, Santiago, 10 de octubre de 1967, Archivo Patricio Aylwin.

5 Tomás Moulián, Fracturas. De Pedro Aguirre Cerda a Salvador Allende (1938-1973), Santiago, Lom, 2006.
} 
sector oficialista que apoyaba los cambios que impulsaba el gobierno de Frei en su carácter y tiempos de implementación.

En ese entonces, la Juventud Demócrata Cristiana libraba un intenso activismo social en el movimiento estudiantil universitario reformista (condujo el movimiento reformista de la Universidad Católica), espacio en el que se explicitaba el énfasis revolucionario, alternativista y anticapitalistas que caracterizaba a los sectores rebeldes y terceristas. Era, por tanto, una juventud particularmente izquierdizada. En 1969, ad-portas de la elección presidencial de 1970, esta JDC enfrentó los dilemas propios de una definición presidencial con un ingrediente añadido: asumió que la pregunta clave a resolver sería cuál era el mejor camino para asegurar un tránsito revolucionario que consolidara una vía de desarrollo no capitalista en Chile. En el partido adulto la proclamación de la candidatura presidencial se inclinó por un líder referente del ala izquierda: Radomiro Tomic. Sin embargo, para el ala DC más conservadora, aunque Tomic era el candidato obvio por ser el otro líder importante del partido, ello no significaba subordinarse a su perspectiva.

Para Tomic, la viabilidad de una vía no capitalista de desarrollo pasaba porque el PDC abandonara la idea del camino propio y abrazara lo que denominó "Unidad social y política del pueblo" o simplemente "unidad popular", y que involucraba una alianza electoral y de gobierno entre la DC y la izquierda marxista. La "Unidad Popular" era una idea que Tomic venía promoviendo sin éxito desde 19636, y que partía de la base de que una "verdadera revolución" conducente a la "sustitución de la actual institucionalidad del Estado y de los centros de poder neocapitalistas y capitalistas ${ }^{* 7}$, necesitaba de una mayoría electoral y de una mayoría movilizada que ni la izquierda ni la DC tenían por sí solas. Sin embargo, ya en abril de 1969 Tomic percibía que ni la izquierda marxista ni la DC estaban dispuestas a tal alianza, razón por la cual envió una carta al presidente del PDC Renán Fuentealba renunciando a ser candidato. ${ }^{8}$ En mayo desistió de tal renuncia y jugó sus cartas para que la Junta Nacional del PDC avalara la idea de "Unidad Popular", pero su tesis perdió por estrecho margen frente a los que optaron por mantener la línea del camino propio. En ese mismo mes, a las dos semanas del fin de la Junta Nacional, militantes de la facción rebelde abandonaron la DC para formar el Movimiento de Acción Popular Unitaria Mapu, que a la postre, se articuló con la izquierda marxista dando lugar a la coalición que tomó por nombre "Unidad Popular".

Entre los Rebeldes que parten hacia el MAPU había militantes de mayor edad como los dirigentes Jacques Chonchol, Rafael Agustín Gumucio, Fernando Jerez y Julio Silva Solar, pero también un importante contingente de militancia y activos simpatizantes de la JDC, donde destacaban los activistas reformistas de la UC encabezados por Miguel Ángel Solar. En un principio, los líderes veteranos concentraron el protagonismo, pero, al poco andar, fueron los cabecillas de la militancia joven dirigida por cuadros como Rodrigo Ambrosio, Enrique Correa, Jaime Gazmuri y Oscar Guillermo Garretón quienes hegemonizaron la conducción del nuevo partido.

\footnotetext{
6 Ver: Radomiro Tomic, “Carta de Tomic a Fuentealba”, Revista Ercilla, Santiago, 2 de abril de 1969, página 9 y 10, Archivo Patricio Aylwin.

7 Idem.

8 Idem.
} 
Ya con la salida de los Rebeldes la JDC quedó muy mermada, mucho más de lo que quedaba el partido adulto, pues, aunque las dirigencias emblemáticas del quiebre fueron adultas, el número proporcional de militantes que abandonaban la DC fue particularmente notorio entre sectores juveniles. ${ }^{9}$ Aun así, las corrientes proclives al énfasis revolucionario y anticapitalista siguieron siendo mayoritarias en la JDC, fundamentalmente por la persistencia de los llamados terceristas.

En agosto de 1969 Radomiro Tomic se convirtió en candidato presidencial de la Democracia Cristiana. Pese a haber perdido la Junta Nacional DC del mes de mayo, y a que el allendismo desestimara permanentemente su tesis unitaria, el abanderado DC insistió en su discurso de convergencia estratégica de las fuerzas revolucionarias en tanto "unidad social y política del pueblo“, y acusó a la Unidad Popular allendista de no ser una Unidad Popular completa. La paradoja de la interna DC fue que, si bien el antimarxismo del freismo había vencido en mantener la línea del camino propio, ello no detuvo los aspectos izquierdistas del programa ni del discurso de Tomic, 10 cuestiones que continuaron movilizando con entusiasmo a la JDC y a su dirección tercerista.

En 1971, sectores terceristas rompieron con la DC, entraron a la Unidad Popular de Allende y se sumaron a la Izquierda Cristiana IC, partido nuevo que surge de la convergencia entre esa militancia y ex MAPU que rechazaron el giro marxista leninista de la conducción de Rodrigo Ambrosio. ${ }^{11}$ De tal modo, la "vieja guardia" Rebelde de raigambre social cristiana encabezada por Chonchol, Gumucio, Jerez y Silva Solar convergieron con cuadros del tercerismo liderados por el diputado Bosco Parra y dirigencias juveniles que venían de liderar a la JDC durante la campaña de Tomic, como Luis Maira (diputado, ex presidente de la FECH, ex coordinador ejecutivo de la campaña presidencial de Tomic), Luis Badilla (ex jefe Nacional de la Democracia Cristiana Universitaria y presidente de la JDC al momento del quiebre), Pedro Felipe Ramírez (ex presidente de la FECH y ex presidente de la JDC) y Antonio Cavalla ( ex presidente de la FECH).

Pese al quiebre de 1971, la JDC siguió siendo mayoritariamente proclive a las nociones de vía no capitalista de desarrollo, socialismo comunitario y "unidad social y política del pueblo“. Por lo mismo, la mayoría de sus militantes continuaron sintiéndose representados por las dirigencias nacionales proclives al ala izquierda de la DC: Tomic, Leighton y el entonces presidente del partido Renán Fuentealba, quien solía resumir la posición ante el gobierno de Allende en los siguientes términos: "somos una oposición revolucionaria a un gobierno revolucionario“. En la interna juvenil, todo esto significó que el liderazgo "tomicista" de Ricardo Hormazábal se impusiera por sobre otros dirigentes fervientemente antimarxistas como Adolfo Zaldívar.

Sin embargo, hacia 1972 las diferencias con la UP crecían, lo que llevó al sector que lideraba Fuentealba a reiterar su anticapitalismo al tiempo que a advertir a la Unidad Popular que la DC no toleraría decisiones y posiciones que se juzgaban como autoritarias, sectarias y contrarias a la democracia. En esa línea, el entonces presidente de la DC declaró en abril de 1972:

\footnotetext{
${ }^{9}$ Moulián, op cit.

10 Edgardo Boeninger, Gobernabilidad, lecciones de la experiencia, Santiago, Uqbar, 2014.

11 Cristina Moyano, MAPU o la seducción del poder y la juventud, Santiago, Ediciones UAH, 2009.
} 
(...) somos una colectividad revolucionaria que estamos en una oposición creciente a un gobierno revolucionario. En efecto, nos hemos definido siempre como un movimiento que lucha por la sustitución del régimen capitalista y la creación de una sociedad socialista, democrática, pluralista y cristiana, que hemos denominado comunitaria. (...) nuestra oposición no nace del hecho de que el gobierno adopte medidas que destruyen el régimen capitalista tradicional, ni de que trate de destruir la oligarquía terrateniente y liberarnos del imperialismo, sino que emana de la comprobación diaria que nos permite afirmar que a través de medios a veces antidemocráticos se desea establecer un nuevo ordenamiento que en nada asemeja a una sociedad socialista, comunitaria democrática (...) Porque lo que estamos observando es que, con prescindencia de la opinión mayoritaria del pueblo, sin la participación real de los trabajadores en las decisiones y en la ejecución, se trata de establecer en nuestro país un Estado Totalitario, al más puro estilo estaliniano, desde arriba hacia abajo, impuesto por una minoría política de dirigentes y burócratas. ${ }^{12}$

Si bien la JDC pasaba por un momento de debilidad en relación a su control de federaciones estudiantiles universitarias, desde 1971 comenzó a ganar presencia en la conducción de los referentes del estudiantado secundario, llegando a presidir la mayoría de los centros de alumnos y algunas federaciones que incluyeron la de mayor connotación nacional: la Federación de Estudiantes Secundarios FESES que reunía a colegios fiscales de Santiago. ${ }^{13}$ Las dos victorias consecutivas de la JDC en elecciones FESES, a fines de 1971 y a fines de 1972, generaron un fuerte impacto a nivel nacional. Primero, porque se trataba de una federación que hasta entonces controlaba la izquierda ${ }^{14}$. Segundo, porque en 1971 se amplió la masa de colegios que la federación representaba y se hicieron por primera vez elecciones directas, lo que constituyó un llamativo barómetro político a nivel juvenil. Tercero, porque la JDC se impuso pese a venir de dos quiebres, mientras que aquellos que emigraron a la Izquierda Cristiana fracasaron al no conseguir un solo representante en el directorio de la federación.

En 1972, el aumento de las tensiones con la UP llevó a la JDC a intensificar un activismo opositor en el espacio público. Entonces, hubo un particular protagonismo en el

\footnotetext{
12 Renán Fuentealba, "Resumen del Informe del Senador Renán Fuentealba Presidente Nacional del PDC al Consejo Ampliado“, Santiago, 18 de marzo de 1972, Archivo Patricio Aylwin.

${ }^{13}$ La FESES agrupaba a los colegios fiscales de formación científica humanista, existiendo otras federaciones para los colegios industriales y técnicos (FEITECH) y comerciales (FECOCH). Por su parte, la federación de colegios particulares FUEP fue creada en 1971. En las elecciones FESES de 1971 la lista de la Democracia Cristiana obtuvo el 41,6 \%, la Unidad Popular el 36,7, el MIR aliado de la Juventud Radical Revolucionaria un 8,5, y la Derecha del Partido Nacional y la Democracia Radical un 7,8\%. Fuente: Jorge Rojas Flores, "Los estudiantes secundarios durante la Unidad Popular, 1970 - 1973“, Historia, número 42, PUC, Santiago, 2009, pp 471 - 503.

14 La izquierda venía de controlar FESES, pero con una serie de tensiones internas que significaron un quiebre en 1969 y la consecuente existencia de dos directivas de izquierda, una socialista apoyada por el MIR, y otra de conducción comunista. Rojas Flores, op. cit, pp 471 - 503.
} 
ámbito estudiantil secundario, donde abundaron las marchas, así como las tomas y retomas de colegios, en rechazo o apoyo a determinadas decisiones de autoridades de gobierno en materia educacional. Y aunque tales situaciones referían a una serie de conflictos puntuales como el nombramiento de un director de colegio o las sanciones a algún estudiante, lo claro es que el aumento de la tensión política a nivel nacional fue lo que hizo de esos conflictos verdaderas batallas por la conquista de las calles. Al año siguiente, lo que estuvo al centro de las disputas entre escolares fue el proyecto gubernamental de Escuela Nacional Unificada (ENU). La FESES con conducción JDC fue central en ese ciclo de movilizaciones y enfrentamientos entre 1972 y 1973. Guillermo Yunge, presidente FESES desde 1971 y Miguel Salazar, presidente FESES desde 1972,15 encabezaron las manifestaciones y emergieron como figuras de importancia nacional y referentes de la JDC y la DC en su posición crecientemente opositora. Juan Claudio Reyes, vicepresidente de la federación en 1972, recuerda hoy:

Yunge gana con facilidad. A partir de ese año la Democracia Cristiana sola gana 64 de los 72 centros de alumnos en los colegios públicos. ${ }^{16}(\ldots)$ Estos que éramos de 16 años, pasamos a tener una importancia al interior de la DC superlativa. Porque las estructuras universitarias pasaron a ser controladas por los jóvenes de la Unidad Popular, los jóvenes universitarios Demócrata Cristianos pierden importancia relativa al interior de la DC y la toman los estudiantes secundarios. Yunge pasa a ser un tipo casi rock star, los que estamos en esa dirigencia secundaria viajábamos por todo Chile para la campaña del 73. (Juan Claudio Reyes)

Aunque la JDC se movilizó contra la UP entre 1972 y 1973, antes de ello muchos de sus líderes llegaron a manifestar cierta simpatía con el tono reformador del gobierno de la Unidad Popular. Ricardo Hormazábal, por ejemplo, recuerda que la noche del 4 de septiembre de 1970 jóvenes de la DC gritaron en el centro de Santiago "viva el 1, viva el 3" en referencia a los candidatos Tomic y Allende que tenían esos números en la papeleta. Hacia 1973 poco quedaba de ese espíritu, pero había, según el propio Ricardo Hormazábal, una distinción fundamental con relación a apoyar o no salidas golpistas: "Creo que, en agosto del 73, estábamos todos convencidos que el gobierno de Allende debía terminar. (...) Una minoría dirigente pensaba que la única salida era un golpe, pero la gran mayoría de los dirigentes respaldaba una salida política". ${ }^{7}$

El enfático rechazo a una salida golpista y una mayor disposición al diálogo se daba, por tanto, en quienes tenían como referente nacional el liderazgo de personas como Fuentealba, Leighton y Tomic, posición que hacia 1973 tendía a ser mayoritaria en la JDC y

\footnotetext{
15 A esas alturas, la polarización fue tal en las elecciones de FESES de 1972, que la federación se quebró. Los estudiantes de la Unidad Popular encabezados por quien fuera el candidato socialista a FESES Camilo Escalona, acusaron irregularidades electorales y desconocieron el triunfo de Miguel Salazar. Rojas Flores, op. cit, pp 471 503.

16 Según prensa de la época, en vísperas de la elección de 1972, la JDC afirmaba que controlaba 45 centros de alumnos de un total de 66. Rojas Flores, op.cit, pp 490.

17 Ricardo Hormazábal, La Democracia Cristiana y el gobierno de Allende, Santiago, Copygraph, 2014, pp 55.
} 
era representada por líderes como Hormazábal, Yunge y Juan Carlos Latorre. Esa línea perdió la presidencia del partido en mayo de 1973 ante una candidatura de Patricio Aylwin que proponía "no dejar pasar ni una” al gobierno. En los testimonios actuales de esos jóvenes dirigentes de entonces, no hay una visión única sobre las correlaciones internas frente a la alternativa golpista. Para Hormazábal, la dureza con el gobierno de Allende era bastante transversal y los abiertamente golpistas eran minoritarios y no involucraban al propio Aylwin. Otros, como Juan Claudio Reyes, enfatizan en que la dureza de Aylwin terminó favoreciendo, en la práctica, las tendencias golpistas:

Si tu lees los discursos de Renán Fuentealba respecto del gobierno de Allende, no vas a notar diferencias salvo de tono con lo que decía Aylwin. Renán le sacaba con razón la mugre al gobierno de Salvador Allende. (...) Entonces la JDC no tuvo conflictos de fondo con esa materia porque teníamos, además, en eso, una gran coincidencia con Aylwin. Yo tengo un testimonio personal, Aylwin nunca estuvo en el golpe, él se equivocó después. (Ricardo Hormazábal)

La campaña de Fuentealba al 73 decía; "somos una oposición revolucionaria a un gobierno revolucionario", esa era la tesis de Fuentealba, y Aylwin, Lavandero y los más derechistas era; "no les dejaremos pasar ni una". Cuando Aylwin le gana a Fuentealba, luego Fuentealba reúne a los jóvenes demócrata cristianos de esa fecha, en el mismo salón de actos de la DC donde gana Aylwin. Aylwin se va retirando del salón y Fuentealba nos dice "ese hombre nos va a llevar al golpe. (Juan Claudio Reyes)

Donde sí tienden a coincidir los citados testimonios de la generación juvenil tomicista de antes del golpe, es en plantear que el triunfo de Aylwin, independiente de si fue o no un factor que favoreció la intervención militar, al menos sí fue una situación que terminó condicionando la actitud de aceptación que tuvo la dirección DC los días posteriores al golpe de Estado. Porque mientras Fuentealba y Leighton encabezaban la lista de trece firmantes de aquella recordada declaración que rechazó el golpe de Estado a dos días del haberse materializado, el mismo día apareció en la prensa bajo el título "Posición del PDC" un escrito que tenía el respaldo de Aylwin y la directiva en un sentido completamente opuesto, como se puede apreciar en los siguientes extractos, el primero, de la declaración de los 13, y el segundo de la directiva DC.

Condenamos categóricamente el derrocamiento del Presidente Constitucional de Chile, señor Salvador Allende, de cuyo Gobierno, por decisión de la voluntad popular y de nuestro partido, fuimos invariables opositores. Nos inclinamos respetuosos ante el sacrificio que él hizo de su vida en defensa de la Autoridad Constitucional. ${ }^{18}$

18 "Declaración Pública", conocida luego como "Declaración de los 13“. En Jorge Donoso y Grace Dunlop Echavarría, Los 13 del 13. Los DC contra el golpe, Santiago, Ril, 2013, pp 163-164. 
Los antecedentes demuestran que las Fuerzas Armadas y Carabineros no buscaron el poder, sus tradiciones institucionales y la historia republicana de nuestra patria inspiran la confianza de que tan pronto sean cumplidas las tareas que ellas han asumido para evitar los graves peligros de destrucción y totalitarismo que amenazaban a la Nación chilena, devolverán el Poder al Pueblo soberano para que soberanamente decidan el destino patrio. Los propósitos de restablecimiento de la normalidad institucional de paz y unidad entre los chilenos expresados por la Junta Militar de Gobierno interpretan el sentimiento general y merecen la cooperación patriótica de todos los sectores. ${ }^{19}$

Al mismo tiempo, la declaración de los 13 manifestaba, nuevamente, lo que había sido la impronta de los sectores proclives a las nociones de "socialismo comunitario", "vía no capitalista de desarrollo" y "unidad social y política del pueblo“, esta vez, mediante una conclusión crítica de la experiencia de la UP. Es decir, junto con la condena al golpe, a este sector le interesó deslindarse también de cualquier orientación restauradora de los intereses monopólicos y de la gran propiedad, destacando que su oposición al gobierno de Allende había sido contra desviaciones sectarias y antidemocráticas presentes en la izquierda y no contra la posibilidad de un proyecto socialista para Chile.

Señalamos que nuestra oposición a su gobierno fue siempre planteada para preservar la continuidad del proceso de cambios que tuvo el honor de iniciar en nuestro país el gobierno de la Democracia Cristiana y al mismo tiempo para impedir su desviación antidemocrática. (...) La falta de rectificación, que en definitiva nos llevó a la tragedia, es responsabilidad de todos, Gobierno y Oposición, porque el deber de mantener una democracia no puede ser eludido por nadie. Pero a nuestro juicio hubo quienes tuvieron mayor responsabilidad. En primer lugar, el dogmatismo sectario de la Unidad Popular, que no fue capaz de construir un camino auténticamente democrático para el socialismo adecuado a nuestra idiosincrasia. ${ }^{20}$

Fue esta diferencia de postura política la que determinó la emergencia de dos corrientes perfectamente distinguibles en el PDC, y particularmente en la JDC. Aunque en 1973 la JDC no se fracturó como sí lo había hecho en 1969 y 1971, los caminos de una y otra posición frente a la dictadura corrieron por cauces de militancia totalmente diferenciados, casi como si se tratara de orgánicas diferentes.

\footnotetext{
${ }^{19}$ Declaración oficial del PDC titulada "Posición del PDC". En, Donoso - Dunlop, op cit, pp 55 - 56.

${ }^{20}$ Declaración de los 13. Op cit.
} 


\section{Chascones y guatones en la JDC. Origen de una distinción. 1973- 1976.}

Durante los meses posteriores al golpe de Estado y en todo el transcurso de 1974, la Democracia Cristiana, pese al receso de los partidos y las restricciones a la vida política, pudo contar con una sede en el centro de Santiago (hasta marzo de 1974 en Alameda, luego en una oficina en Calle Huérfanos), y logró mantener reuniones periódicas donde se coordinaban las principales dirigencias a nivel del partido y la juventud. En tales reuniones, el debate central fue la posición de la DC ante el gobierno. Las tesis que circularon, en general, experimentaron cambios a medida que el propio régimen se desarrollaba. Mientras dirigentes como Juan de Dios Carmona y William Thayer hablaron de un "deber patriótico" de colaborar con la Junta Militar, los dirigentes identificados con la declaración de los 13 permanentemente rechazaron tal idea, y hacia 1974 aunaron criterios en torno a promover una oposición explícita y activa a la dictadura.

En el mismo año, la dirección de Aylwin sostuvo que lo fundamental del momento, más que definirse entre el apoyo o la oposición, era salvar al partido o "preservar el cuerpo y alma de la Democracia Cristiana“. Años más tarde Aylwin planteó que tal posición significaba combinar la consecuencia con la prudencia:

Salvar el alma exigía mantener nuestra dignidad moral. Ser consecuentes con nuestros principios, afirmar nuestra verdad, defender los derechos humanos, buscar la justicia, ser solidarios con los sufrientes. Salvar el cuerpo exigía ser prudentes y astutos, no exponernos a las iras de los poderosos, actuar con cuidado y lograr mantener una organización adecuada a las circunstancias..$^{21}$

Salvar el cuerpo, o la estructura del partido, desde el imperativo de la prudencia en tanto independencia de posturas oficialistas y opositoras, resultó intolerable para las corrientes vinculadas a la declaración de los 13. Un fuerte énfasis antidictatorial, la lectura histórica contraria al golpe de Estado, la exasperación ante cualquier signo de condescendencia, aceptación o colaboración respecto al régimen, sumado a la conciencia y rechazo en torno al grado de violencia y represión que ejercía el gobierno, chocó dramáticamente con la postura oficial del partido, como lo expone una carta de Gabriel Valdés al presidente de la DC fechada en febrero de 1974:

La tesis: militares a corto plazo, DC a largo plazo, no solamente era ingenua sino mortal desde el punto de vista de los principios esenciales de la DC y de la subsistencia del partido. Así fue estimado unánimemente por nuestros amigos europeos, que algo saben de fascismo. (...) La justificación moral para estar en la oposición a la UP residió en el temor a una dictadura. Y esa oposición se realizó sin escrúpulos, a fondo, sin parar mientes en las consecuencias. Esa moral no era objetiva. No se aplicó frente a los derechos humanos

${ }^{21}$ Aylwin, Patricio Aylwin, El reencuentro de los demócratas, Santiago, Ediciones Grupo Zeta, 1998, pp 50 
aplastados, a los campos de concentración, a las turturas (sic). A veces no se creían. Cuando le he dicho a un camarada: B.B, militante de la Izquierda Cristiana, amigo mío y de mis hijos por años, ha quedado con sus facultades mentales perturbadas al parecer para siempre y no puede valerse por sí mismo por las torturas que sufrió, me ha contestado: "siempre se producen excesos"!!! Primero se perdió al alma. Ahora el cuerpo. Sin pena ni gloria. ${ }^{22}$

Pero, dadas las condiciones del llamado "receso partidario",23 la resistencia a la línea representada por Aylwin difícilmente podía disputar su hegemonía. La directiva controlaba la estructura, y a fines de 1974 ese control se expresó en los resultados de una consulta efectuada al plenario nacional ${ }^{24}$ sobre la posición del partido en torno al gobierno. Ahí, el régimen se definió como dictadura, y ante él se estableció como política una "independencia crítica y activa", tesis que se impuso por sobre la de "oposición frontal". 25

Durante toda la presidencia de Aylwin en la DC, o sea, hasta 1976, la opción de la Democracia Cristiana por no aparecer oficialmente como opositora, coincidió con la negativa a cualquier tipo de vínculo, acuerdo y política en común con la izquierda. Un ejemplo temprano de la oposición que ello generaba en el sector vinculado a la declaración de los 13 es la ya citada carta de Gabriel Valdés a Aylwin, en la que el ex canciller anuncia, en tono profético, que la reconstrucción democrática pasará por nexos entre una renovada DC y una izquierda que estaba siendo perseguida: "La restauración democrática - que vendrá requerirá una limpieza frontal en el partido, un cambio de sistema, de orientación política y objetivos estratégicos. Será una tarea larga cuyo éxito estará unido al entendimiento con quienes sufrieron primero - sin defensa nuestra- los rigores de la violencia injusta. '26 Un año más tarde, tal idea fuerza se repitió en una carta fechada en abril de 1975 que Bernardo Leighton, Renan Fuentealba, Claudio Huepe, Radomiro Tomic y Ricardo Hormazábal enviaron a Aylwin en tanto presidente de la DC27. Ahí se hacían comentarios a la línea oficial del partido y los firmantes exponían su punto de vista en torno a una convergencia antidictatorial con partidos marxistas, que aunque no constituyera un frente formal (Frente Antifasista habían

22 Gabriel Valdés, "Carta de Gabriel Valdés a Patricio Aylwin, Presidente Nacional del Partido Demócrata Cristiano, sobre la posición que ha tenido la Directiva Nacional en su relación con la Junta Militar", 27 de febrero de 1974, Archivo Patricio Aylwin.

23 El Decreto Ley 77 de octubre 1973 dictaba: "Prohíbense, y, en consecuencia, serán consideradas asociaciones ilícitas, los Partidos Comunista o Comunista de Chile, Socialista, Unión Socialista Popular, MAPU, Radical, Izquierda Cristiana, Acción Popular Independiente, Partido de la Unidad Popular y todas aquellas entidades, agrupaciones, facciones o movimientos que sustenten la doctrina marxista." Por su parte, el decreto Ley 78 del mismo mes y año, establecía el receso de todos los partidos considerados no marxistas y no incluidos en el decreto 77. En marzo de 1977 la dictadura, mediante el decreto 1.697, decretó la disolución de todos los partidos existentes antes del 11 de septiembre de 1973, lo que ha sido interpretado como un golpe a la Democracia Cristiana, pues el Partido Nacional ya se había autodisuelto. Un análisis al respecto en: Luis Corvalán Márquez, Del anticapitalismo al neoliberalismo en Chile, Santiago, Editorial Sudamericana, 2001.

24 Entonces, el Plenario Nacional se componía de la mesa directiva, el Consejo Nacional, representantes de parlamentarios, representantes de regidores y presidentes zonales, todos ellos elegidos previamente al golpe.

25 Aylwin, El Reencuentro..., op cit.

26 Valdés, op cit, Archivo Patricio Aylwin.

27 Según Aylwin, Gabriel Valdés estaba entre los que apoyaron la carta, y no firmó sólo por tener un cargo en Naciones Unidas. Aylwin, op cit, pp 110. 
propuesto sectores de la ex Unidad Popular), si implicara establecer objetivos y acciones en común: "En cuanto al rechazo al Frente Amplio, teníamos entendido que se referiría a su constitución orgánica, pero no a la posibilidad de un trabajo convergente con los partidos marxistas y con otros, hacia objetivos moralmente aceptables que pasan a ser patrióticamente obligatorios, respecto al presente y al provenir de Chile. Negarse a esto sería tan dogmático como inexplicable. " 28 La respuesta de Aylwin fue rotunda y también un claro ejemplo de la línea oficial en relación a la izquierda: "Pensar que para la tarea de construir en Chile una nueva democracia pudiera ser necesario o conveniente alguna forma de colaboración, o acuerdo con el PC o con el PS del señor Altamirano - aparte de que significa ignorar las condiciones objetivas de la realidad chilena- es como proponer entregar el queso al cuidado del ratón. Podrán ellos colaborar a terminar esta dictadura; pero no para establecer una democracia, sino para sustituirla por su dictadura".29

En definitiva, la diferencia radical entre las dos posiciones pasaba por el modo en que se vislumbraba un retorno a la democracia. Para el sector opositor a la directiva, la salida requería de una convergencia amplia para enfrentar la dictadura y rechazarla; para la directiva, según el análisis posterior del propio Aylwin, el camino consistía en "buscar el retorno a la democracia mediante un acuerdo con los militares, es decir, con las fuerzas armadas y no contra ellas", agregando que "dentro de ese cuadro, cualquier acercamiento nuestro a socialistas y comunistas, satanizados como enemigos de la patria, suscitaría la desconfianza de los militares y obstacularizaría el éxito de nuestra política". ${ }^{30}$

Mientras tanto, en la JDC este debate condicionó un cambio de directiva en 1974. Para entonces, la mesa ejecutiva estaba dividida en dos tesis. Por un lado, la que defendía el entonces presidente de la Juventud, Ricardo Hormazábal, y el dirigente Edgardo Riveros, que proponía una oposición activa y explícita al régimen. Por otro lado, la postura que promovió el entonces vicepresidente, Gutenberg Martínez, junto con los dirigentes Juan Carlos Latorre y José Miguel Fritis, la que calzaba plenamente con las ideas fuerza que caracterizaron la posición de Aylwin y la directiva adulta: prudencia para resguardar la orgánica del partido, e independencia crítica y activa. Se realizó una consulta entre dirigentes regionales respecto a dos documentos, sin firma, que sintetizaban una y otra tesis. La militancia recuerda que un grupo de personas fue la encargada de recorrer el país con los documentos escondidos en cajas de fósforos, no dejando copias, sino simplemente leyendo cada texto y anotando los votos. Para buena parte de quienes entonces se alinearon con los argumentos de Hormazabal, el extremo cuidado de la clandestinidad durante la consulta se mezcló con ciertas desprolijidades que, a propósito, o casualmente, terminaron favoreciendo la tesis defendida por Martínez. Como lo indica Andrés Palma, entonces estudiante de la escuela de economía de la Universidad de Chile:

Hubo un grupo de personas que recorrió el país con los documentos sin firmar y los documentos sin reproducir. Yo no conocí cuáles eran los documentos, yo supe de su existencia. Los que viajaban llevaban las tesis en cajas de fósforo: por eso (le llamaron) el plebiscito de las

\footnotetext{
28 Bernardo Leighton, Renán Fuentealba, Claudio Huepe, Radomiro Tomic y Ricardo Hormazábal, "Carta a Patricio Aylwin, presidente de la Democracia Cristiana“, 7 de abril de 1975, Archivo Patricio Aylwin.

29 Patricio Aylwin, "Carta de Patricio Aylwin a Bernardo Leighton", 5 de mayo de 1975, Archivo Patricio Aylwin.

30 Aylwin, El Reencuentro... op cit, pp 112.
} 
cajas de fósforo. Las leían a las personas que tenía que elegir cuál era la tesis. No se las pasaban. En el caso de la Escuela de Economía, la persona que tenía que votar era nuestro jefe de Escuela, que era Elías Sánchez, gran chascón, gran militante que falleció el año 79 en un accidente. Y a él le tocaba votar en ese plebiscito porque era el jefe de la escuela y no lo encontraron, misteriosamente no lo encontraron, entonces votó Luis Ajenjo que había sido jefe, pero ya no era el jefe y que representaba la posición de Gutenberg Martínez. En cambio, Elías Sánchez representaba la posición de Ricardo Hormazábal. Ahí empezaron a haber oscurantismos que uno supiera en los procesos de la JDC. (Andrés Palma).

Finalmente, en un universo de no más de 50 personas obtuvo mayoría la tesis propuesta por Martínez. Aunque la derrota no obligaba a Hormazábal a renunciar a la presidencia, éste prefirió hacerlo y quedó conformada una nueva mesa de conducción encabezada por Gutenberg Martínez. Hormazábal recuerda al respecto:

Empezaron a surgir los problemas con un sector de la JDC. Como los riesgos eran muy altos, ese grupo empezó a plantear que no podíamos seguir arriesgándonos. Influidos también fuertemente por un sector del partido adulto: Osvaldo Olguín, Hamilton, Andrés Zaldívar, Rafael Moreno, toda esa gente que no estaba por entrar a un conflicto con la dictadura. Los sectores más progresistas nos reuníamos los martes en la casa de Don Ignacio Palma y entonces venia Benjamín Prado de Valparaíso, estaba Belisario Velasco, Renán (Fuentealba). Los que habíamos condenado el golpe, los que creíamos que había que mantener al partido activo para defender los valores (...). Gutenberg, el Kako (Juan Carlos Latorre), José Miguel Fritis empezaron a decir "no nos arriesguemos, aquí vamos a tratar de mantener algunos cursitos de formación, algunas actividades menores, pero nada de riesgo“. Edgardo Riveros estuvo de acuerdo conmigo, yo era el presidente. 3 a 2 era la relación en la directiva. Hicimos una consulta entre una tesis A y una tesis B. El documento de Gutenberg lo redactó Mario Fernández y tenía un encabezamiento de una cita de Radomiro que era muy importante pa nosotros. Y yo, con pretensiones intelectuales había terminado de leer "La divina comedia" del Dante y puse (una cita sobre) el círculo donde quedan aquellos que nunca toman decisiones ${ }^{31}$. Entonces perdió mi tesis. La verdad es que no fue debate, porque se llevaban documentos y no se decía de quien eran. Yo renuncié, porque yo no pude aceptar seguir a cargo en una estrategia que no comparto. Perdí mi tesis y renuncié. Cuando se supo que yo había renunciado,

31 Probablemente Hormazábal se refiere al anteinfierno o vestíbulo de los cobardes. 
Don Patricio (Aylwin), que yo le fui a comunicar, me dijo: "Ricardo no, acuérdese que, de acuerdo con el estatuto de emergencia, el presidente concentra el poder, así que si usted quiere eche a todos los que están en desacuerdo con su tesis". No, Don Patricio, le dije, yo no creo en eso, hicimos una consulta y yo acepto los términos de la consulta por lo tanto me voy. (Ricardo Hormazábal).

A partir de entonces, en la juventud de la Democracia Cristiana hubo dos modos de proceder. Por un lado, el que asumió plenamente las orientaciones que realizaba la directiva, evitando pronunciamientos públicos de oposición al régimen, la participación en manifestaciones antigubernamentales, y todo tipo de activismo sectorial conectado con la izquierda. Por otro, un actuar rebelde ante las orientaciones oficiales, que practicó un intenso activismo opositor, que estableció vínculos con la izquierda clandestina y que se desarrolló fundamentalmente a partir de dos instancias: los esfuerzos de rearticulación del movimiento estudiantil, y el activismo público en defensa de los derechos humanos.

Al tener motivaciones, diagnósticos y prácticas tan diferentes, estas posiciones desarrollaron espacios de militancia paralelos, dos corrientes, con referencias a los debates del partido adulto, pero con origen y especificidades radicadas en la militancia juvenil: la corriente de los "guatones" (chilenismo: panzones, barrigudos) y la corriente de los "chascones" (chilenismo: greñudos, de pelo desordenado y eventualmente largo). En el nombrar a estos grupos, hubo una mezcla de factores. Fundamentalmente, se trataba del nombre con que un sector o corriente señaló al "otro " con quién difería tanto en las tesis políticas como en las prácticas y espacios concretos de militancia. De modo que, más allá de cierta coincidencia que algunos testimonios ven entre algunos líderes de cada corriente con los tipos físicos y de estilo del "guatón" o "chascón", indudablemente estamos hablando de metáforas políticas. Para los "chascones", el término "guatón" simbolizaba una militancia con poca actividad, conservadora, sedentaria, y que prefería la comodidad al riesgo. Por su parte, el apelativo chascón, para los "guatones", hacía referencia a quién había sido unos de los líderes de la corriente rebelde que formó el MAPU en los años sesenta y que luego fundó la IC, Fernando Jerez, quien usaba el pelo relativamente largo y era conocido como "Chascón Jerez". Llamar a los otros "chascones“"era, de alguna manera, recordar una amenaza radicada en cierto izquierdismo que en el pasado había significado la división del partido, al tiempo que referir al desorden, al desordenar - chasconear una práctica militante que debía estar sujeta a una norma y jerarquía. De tal modo, cada nombre es, en parte, el nombre que da el otro, aunque al mismo tiempo, terminó siendo el nombre que los propios militantes terminaron asumiendo para sí, dando lugar a identidades autoreferidas como chasconas o guatonas.

Lo de Chascones viene del lote de Yunge que eran chascones. Todos usábamos el pelo largo. Después del Golpe el grupo de Miguel Salazar que era seguidor de Gute, empezó a engordar. Y ahí terminó en los Chacones y los Guatones. (...) El nombre viene claramente de la juventud, no del partido. (Andrés Palma) 
Los chascones, la historia se conoce, viene de Alberto Jerez, con su mechón que se lo peinaba a cada rato. (Juan Claudio reyes)

Lo de los guatones viene de imágenes de apoltronados, la idea de que vivían sentados, sin movilidad. Y los otros, los chascones que no aceptan disciplina, jerarquía. Para unos, son los chascones que chasconean, que se salen de los cauces. Y los otros, los guatones que no hacen nada, que no se mueven, que prefieren estar ahí siempre gestionando, dirigiendo en el poder y la comodidad. (Rodolfo Fortunatti)

Los chacones le ponen (el nombre) a los guatones y los guatones le ponen (el nombre) a los chascones. (Humberto Burotto)

El punto en donde chascones y guatones coincidían era en la necesidad de apoyar a las víctimas de la violencia estatal, colaborar con las organizaciones civiles y eclesiásticas de defensa de los derechos humanos y prestar servicios profesionales con abogados que presentaban los recursos de amparo, recababan información y hacían seguimiento a cada denuncia. La diferencia era que mientras para los guatones ello era la labor humanitaria y cristiana que el partido debía asumir con prescindencia de un activismo expresamente opositor, para los chascones tal accionar debía enmarcarse en una lucha política por la democracia en donde la DC fuera abiertamente opositora y buscara aliados políticos para gestionar dicha oposición. A decir de Humberto Burotto: “La lógica del testimonio (contra la dictadura) era chascona, la lógica de generar y mantener la estructura era guatona. La lógica de agruparse en torno a la realidad de los derechos humanos era global, era de todos, pero la lideraban los chascones".

En esta conformación de las posiciones, practicas e identidades en disputa, el proceder de la dictadura hacia la propia Democracia Cristiana fue un factor relevante, pues no obstante sus mayores facilidades de funcionamiento y reunión (en comparación con la izquierda), la DC era continuamente vigilada y paulatinamente comenzaba a recibir hostigamiento y represión en la persona de sus líderes más declaradamente opositores, con situaciones que iban desde la censura a textos y medios, hasta la detención, relegamiento, exilio y tortura de algunos militantes. La primera gran figura de la DC en enfrentar la dureza del régimen fue Bernardo Leighton, a quien se le prohibió ingresar a Chile en octubre de 1974 luego de unas declaraciones dadas en Europa. En el mismo año el exdiputado DC Claudio Huepe fue detenido por agentes de la DINA y expulsado del país luego de pasar cuatro meses preso en campos de concentración. La misma pena de exilio recayó en el ex presidente del partido Renán Fuentealba acusado de desafiar a la autoridad y "comprometer el prestigio de Chile" en declaraciones dadas a una agencia noticiosa extranjera. En 1975 funcionarios de la DINA destruyeron y sacaron de circulación un libro del dirigente DC Claudio Orrego; se clausuró temporalmente el medio ligado al partido y dirigido por Belisario Velasco "Radio Balmaceda"; 32 se prohibió la circulación de la revista Política y Espíritu; fue detenido y torturado en Talca el presidente provincial de la DC José Muñoz; fue detenida por la DINA la militante Eliana Ávalos; fueron detenidos en Tres Álamos Luis Aguayo, Leonel Tapia y Reinaldo Villegas, académicos demócrata cristianos exonerados de

32 Belisario Velasco, Esta historia es mi historia, Santiago, Catalonia, 2018, pp 178 -180. 
la Universidad del Norte; fueron despedidos, detenidos, torturados y relegados un grupo de dirigentes sindicales DC de El Salvador, Barquitos y Potrerillos; fue detenido y torturado el ex diputado DC Pedro Araya; y en el mes de octubre la DINA atentó contra Leighton y su esposa Ana María Fresno en Italia, dejándolos con graves secuelas. ${ }^{33}$ En marzo de 1976 fue nuevamente clausurada radio Balmaceda y su director, Belisario Velasco relegado a Putre. En el mes de octubre fue detenido y expulsado del país el exministro, abogado e intelectual Demócrata Cristiano Jaime Castillo, junto al también jurista y militante del PIR (Partido de Izquierda Radical ${ }^{34}$ ) Eugenio Velasco. Ambos habían sido firmantes de una carta dirigida a los cancilleres reunidos en Santiago con motivo de la reunión anual de la OEA.

Es decir, el ser y actuar como opositor significaba exponerse a la represión, cuestión que estaba en la base de la advertencia de mesura de los "guatones": "salvar el cuerpo", "cuidar la estructura", "no exponerse"; pero también en la exigencia ética que hacían los chascones al partido, que señalaba que no era correcto ser prescindente ni neutral, que había que desarrollar un testimonio anti dictatorial porque amplios sectores del país eran víctimas y porque los propios DC estaban siendo víctimas.

Hacia la segunda mitad de los años setenta la diferencia en las posiciones y prácticas hizo de los chascones de la JDC prácticamente una orgánica diferenciada de la estructura formal de poder que controlaban los guatones. En definitiva, al no tener la posibilidad de generar un debate conducente a una nueva dirección de la JDC, la apuesta chascona fue el paralelismo en los hechos, aunque este paralelismo no buscó el quiebre, y la JDC no protagonizó una división del partido como había ocurrido con el MAPU y la IC. Juan Claudio Reyes y Gustavo Rayo recuerdan al respecto:

Hacíamos declaraciones públicas firmando como Juventud de Chile -JDC, porque era claramente un paralelo. No había elecciones internas, por lo tanto, no había democracia interna donde esto se pudiera discutir. (...) En la JDC, dada la relación entre Gutenberg Martínez y Patricio Aylwin, el rol de la Democracia Cristiana era cuidar su estructura. Y cuidar la estructura significaba no hacer nada para que no te reprimieran. (Juan Claudio Reyes)

Gutenberg asume la presidencia de la Juventud, y ya nosotros actuamos como grupo aparte. La estrategia de Gutenberg Martínez en su dirección de la Juventud era proteger la organización y eso significaba que no era conveniente involucrarse en actividades que significasen un riesgo para la organización. $Y$ nosotros todo lo contrario. Nuestra postura era regenerar un movimiento estudiantil, intentando activar un movimiento de Derechos Humanos, y esas dos tareas las entendíamos como una tarea que debía estar abierta a todos los sectores o grupos juveniles, juventudes políticas diversas. (...) La primera vez que yo fui detenido fue el año 76 y fue panfleteando en el café Haití y teníamos un panfleto que era del

\footnotetext{
33 Aylwin, El reencuentro... op cit, pp 103 - 104.

34 Entidad creada en 1971 a partir de una división del Partido Radical. En un inicio mantuvo su apoyo a la Unidad Popular pero luego pasó a la oposición.
} 
aniversario del partido. Pero con una postura anti-dictatorial, por crear espacios de libertad. Y ahí firmábamos como Juventud de Chile, pero con la J bien grande, la $\mathrm{D}$ bien grande y la $\mathrm{C}$ bien grande, para hacer referencia de que éramos la Juventud Demócrata Cristiana. (Gustavo Rayo).

De todos modos, la política de Aylwin de mesura con vistas a un acuerdo con los militares y de distancia respecto a la izquierda, había sido innegablemente golpeada por la dureza represiva del gobierno. En octubre de 1976 Aylwin, reconociendo su cansancio, dejó la presidencia del partido y nombró una directiva provisoria encabezada por Andrés Zaldívar, directiva que a su vez debía organizar una consulta al plenario nacional desde donde emanaría la directiva definitiva y los lineamientos políticos del partido. En este marco, se distribuyeron para el debate dos textos representativos de las fuerzas que disputaban la conducción. Por un lado, un documento firmado por Tomás Reyes que se titulaba "Nuestra fuerza política y social al servicio de la recuperación democrática", por el otro, un documento firmado por Andrés Zaldívar en su condición de presidente provisorio.

Si bien el escrito de Reyes resultaba afín a los "chascones" y el de Zaldívar a los "guatones", su lectura sugiere cambios en lo que había sido el enfrentamiento de ideas durante la presidencia de Aylwin. El texto firmado por Reyes tenía un tono particularmente enfático en el rechazo a la dictadura, las violaciones a los derechos humanos y los abusos del autoritarismo. En torno a los vínculos con la izquierda, si bien rechazaba la idea de un frente amplio antifascista en tanto alianza política formal con miras a la lucha por la democracia y un nuevo gobierno (estimaba que aún no estarían maduros los análisis autocríticos para una alianza de ese tipo), sí se refería en buenos términos a los revisionismos del mundo socialista y a los eurocomunismos, en el sentido de su aceptación de la democracia como valor esencial. Proponía una amplia unidad opositora, pero no como alianza de partidos sino a nivel de las bases y de la mano de los movimientos sociales: "el movimiento por la recuperación democrática en defensa de la justicia debe surgir desde la base social sin exclusiones, en forma que sea posible mantener y sostener las diferencias politicas sin dañar u atentar contra la unidad básica que debe existir en las organizaciones sociales. "35

Por su parte, el texto de Zaldívar, aunque representaba una línea de continuidad con la política de la directiva anterior, tenía indudablemente un tono y un contenido más marcadamente opositor y de rechazo frente al régimen. Sostenía la denuncia y el testimonio en la defensa de los derechos humanos como elementos centrales para impulsar un camino a la democracia, así como la crítica a la política económica y la elaboración de una plataforma para un futuro gobierno democrático. Este camino sería gradual, y se era categórico en rechazar que "la caída de la dictadura es un hecho abrupto y total"36. En el plano de las alianzas, hay un mayor énfasis en la prescindencia de lo que ocurra en la Unidad Popular ("La política demócrata cristiana es pues, independiente y ajena a los avatares de esa agrupación política“37) y en

35 Tomás Reyes, “Nuestra fuerza política y social al servicio de la recuperación democrática”, enero de 1977, Archivo Patricio Aylwin, pp17.

36 Andres Zaldivar, "Documento político presentado al Plenario del PDC", diciembre de 1976, Archivo Patricio Aylwin, pp 7

37Ibid. 
conservar una distancia con el Partido Comunista. En lo general, se deja abierta la posibilidad de promover con grupos y personas afines a la Unidad Popular "un debate y una confrontación generosas en torno de temas (...) que puedan conducir a importantes cambios en los programas y la práctica política, de manera de garantizar en las ideas y en los hechos una adhesión sincera y responsable a los ideales democráticos" 38 . Por último, plantea la necesidad de la unión de los humanistas a nivel de un movimiento social fuerte y autónomo, "que exprese una misma convicción política y moral".39

El plenario nacional de marzo de 1977 entregó la presidencia de la DC a Andrés Zaldívar y la primera vicepresidencia a Tomás Reyes. En el mismo mes, el gobierno sacó a la luz pública los documentos de Zaldívar y Reyes, ${ }^{40}$ acusó a la DC de subversión y decretó la disolución de los partidos políticos existentes antes de 1973, medida que, tal como se mencionó, atacaba exclusivamente a la Democracia Cristiana (la izquierda había sido prohibida con anterioridad y el PN se había autodisuelto) y tuvo como consecuencia la confiscación de sus propiedades.

Tras el cambio de directiva, la postura de la DC frente a la dictadura y la oposición quedó zanjada en el documento partidario emitido el 6 de octubre de 1977 y que fue titulado "Una patria para todos". ${ }^{41}$ Este texto, redactado por Jaime Castillo Velasco, es considerado la base de una nueva disposición, esta vez, favorable a la articulación de un movimiento opositor con otros sectores políticos y con fuerte protagonismo social, lo que se defino como "reagrupamiento del pueblo chileno" en busca de la "restauración democrática". El documento no trataba el tipo de alianza política que debía gestar la DC con otros partidos, dejando atrás la discusión sobre la pertinencia o no de un frente político antifascista, sino que más bien proponía que los partidos se pusieran al servicio de un movimiento nacional tras el objetivo de la restauración democrática.

Naturalmente, "Una Patria para Todos" se prestó para interpretaciones con distinto énfasis. Para la juventud chascona, fue una señal a favor del activismo democratizador con acento en la defensa de los derechos humanos y la recomposición de la sociedad organizada a nivel de base, en donde el imperativo de la unidad social daba legitimidad al trabajo conjunto que se daba con la izquierda en frentes sectoriales como el estudiantil, poblacional y de trabajadores. Sin embargo, los chascones de la JDC seguían sin controlar su estructura partidista encabezada por Gutenberg Martínez, por lo que en la práctica mantuvieron cierto paralelismo orgánico, y sus acciones y posiciones les significaron ser llamados constantemente al Tribunal Supremo bajo acusación de indisciplina, como recuerda Juan Claudio Reyes:

Éramos llevados a los tribunales supremos del partido por estar haciendo cosas al margen de la institucionalidad. Hay un caso tremendo el año 78-79, Jaime Castillo Velasco se declara en huelga de hambre en Caracas, porque le impedían el retorno a Chile y un

\footnotetext{
38 Op cit, pp 16.

39 Op cit, pp 22.

40 Aylwin. El reencuentro... op cit.

41 Partido Demócrata Cristiano, “Una Patria Para Todos“, 6 de octubre de 1977. En: Eugenio Ortega y Carolina Moreno compiladores, ¿La concertación desconcertada? Reflexiones sobre su historia y su futuro, Santiago, Lom, 2002.
} 
grupo de personas organizamos un ayuno en la Iglesia San Francisco, cinco jóvenes, Rodolfo Fortunatti, Pancho Garay, Lucho Toro, yo e Ignacio Walker, que era abogado externo de la Vicaría. El presidente de la Juventud Demócrata Cristiana nos pasa al Tribunal de Disciplina, por estar politizando un gesto moral como el de Castillo. (Juan Claudio Reyes)

Aun así, el activismo en frentes sociales, a contrapelo de la dirección partidaria juvenil, les permitió a los chascones de la JDC consolidar su protagonismo en la recomposición del movimiento estudiantil y en el activismo de derechos humanos. Para todo esto, contaron con una plataforma articuladora de redes y con visibilidad nacional, como fue la Comisión de Derechos Juveniles CODEJU que abordaremos en el siguiente punto.

- La JDC chascona, el CODEJU y el movimiento estudiantil. (1978- 1983).

A nivel estudiantil, la segunda mitad de los años setenta fue de control autoritario de las instancias de representación: los centros de alumnos y las federaciones. Fueron los gremialistas dirigidos nacionalmente por Jaime Guzmán los designados en instancias como la federación de la Universidad Católica FEUC y los órganos federativos de la Universidad de Chile: primero el Consejo Superior Estudiantil y luego la Federación de Centros de Alumnos FECECH. Hacia fines de la década, la intervención de los centros de alumnos y federaciones se abrió a modalidades de elección indirecta vía delegados. Por lo general, se trataba de mecanismos con base en los cursos y que daban protección a la continuidad de las directivas gremialistas (por ejemplo, con votos decisivos de directivas salientes). ${ }^{42}$

En este contexto, los estudiantes de oposición hacían esfuerzos por recuperar confianzas y enfrentar el miedo cotidiano a la represión. Hubo aquí al menos tres dimensiones que se complementaron en el trabajo desde las organizaciones sociales y la militancia política. Por un lado, una labor de organización artístico cultural expresada en redes de talleres, como fue el caso de la Agrupación Cultural Universitaria de la Universidad de Chile, que tuvo claro dominio de las fuerzas de izquierda en su conducción. ${ }^{3}$ Por otro lado, el activismo de derechos humanos, que implicaba acompañamiento y defensa de las víctimas, así como acciones de denuncia. Y finalmente, el esfuerzo por la rearticulación de un movimiento estudiantil opositor a la dictadura, a la intervención autoritaria de las universidades y a las reformas neoliberales de autofinanciamiento universitario.

Este último se enfocó primero en generar espacios de participación a contrapelo de las designaciones, como los colectivos denominados "comités democráticos" para luego apostar por democratizar las instancias de representación estudiantil, luchando por instalar elecciones universales y directas de centros de alumnos y federaciones. La JDC chascona fue particularmente protagónica en el activismo de derechos humanos y de recomposición del

42 Víctor Muñoz Tamayo, Generaciones. Juventud universitaria e izquierdas politicas en Chile y México (Universidad de Chile-UNAM 1984-2006), Santiago, LOM, 2011. Diego García Monge, José Isla, Pablo, Los muchachos de antes. Historia de la FECH 1973 - 1988, Santiago, Universidad Alberto Hurtado, 2006.

43 Víctor Muñoz Tamayo, ACU Rescatando el asombro. Historia de la Agrupación Cultural Universitaria, Santiago, Calabaza del Diablo, 2006. 
movimiento estudiantil, contando para ello con liderazgos públicos que incluso alcanzaron notoriedad en medios de comunicación, como Guillermo Yunge, que había sido presidente de la FESES durante la Unidad Popular.

En ese proceso, comenzaron también a desarrollarse las primeras manifestaciones públicas de oposición al régimen en la forma de fugaces mítines de denuncia de las violaciones a los derechos humanos o protestas en las fechas emblemáticas del primero de mayo o 4 de septiembre (día de las elecciones presidenciales), las que eran objeto de una fuerte represión policial. Poco a poco, se empezaron a desarrollar también sonajeras de cubiertos en los casinos universitarios en protesta por el alza en las matrículas y aranceles, ayunos en solidaridad con sancionados o detenidos, asambleas que discutían sobre la representación estudiantil, así como expresiones públicas de solidaridad con estudiantes y profesores expulsados. Un ejemplo temprano de este tipo de manifestaciones universitarias se dio en 1976, con motivo de la exoneración del académico de la Universidad de Chile y militante demócrata cristiano Máximo Pacheco. Guillermo Yunge, en una entrevista publicada en 1977, describe este suceso de la siguiente manera: "Cuando el año pasado echaron a varios profesores de la escuela de derecho, hubo una importantísima reacción de afecto y solidaridad de los estudiantes. El día que Máximo Pacheco dio su última clase, cerca de 500 estudiantes corearon su nombre en el hall de la escuela".44 Todo ello configuró, hacia 1978, la dinámica de un movimiento estudiantil que comenzaba a rearticularse en post de la democratización, los derechos humanos y la resistencia a los proyectos de transformación estructural e institucional que la dictadura estaba aplicando en el país y las universidades.

En esos años, Guillermo Yunge era una voz pública de los sectores más activamente opositores, los mismos que más tarde rechazaron la consulta convocada por Pinochet para el 4 de enero de 1978 en la que se buscaba promover un respaldo al régimen ante las condenas de las Naciones Unidas por sistemáticas violaciones a los derechos humanos. Días después de la consulta, el 13 de enero, Yunge y otros 11 militantes de la DC fueron detenidos y relegados al extremo norte del país por decreto del Ministerio del Interior, acusados de haber asistido a una reunión política en la oficina del joven dirigente. ${ }^{45}$ La lista de castigados la integraba Tomás Reyes, Andrés Aylwin, Samuel Astorga, Belisario Velasco, Ignacio Balboltín, Juan Manuel Sepúlveda, Hernán Mery y Miguel Hernández por la DC; más los dirigentes de la JDC Guillermo Yunge, Juan Claudio Reyes y Elías Sánchez. 46 El grupo de relegados tenía en común que todos sus miembros asumían los contenidos de Una Patria Para Todos en tanto invitación a generar movilización social en conjunto con las fuerzas de izquierda, es decir, eran todos asociados al mundo chascón.

El documento Una Patria Para Todos trata de ir más allá de las tesis del frente antifascista o de la unidad de los partidos. La tesis de Jaime Castillo: la convergencia en la base. Nosotros entendíamos la convergencia en la base, como la convergencia de lo que se pudiera.

\footnotetext{
44 Entrevista a Guillermo Yunge, "Los jóvenes, después de Chacarillas”, Revista Hoy, Santiago, 10 de agosto de 1977, pp 25.

45 “'Relegados. Tiempo de regresar", Revista Hoy, Santiago, 8 al 14 de marzo de 1978, pp 14 y 15.

46 Velasco, "Esta historia.... Op cit, pp 221.
} 
(...) Esta tesis sirve para darle legitimidad a todas las luchas sociales de convergencia con la izquierda. (Rodolfo Fortunatti)

Para Juan Claudio Reyes, entonces estudiante de sociología de la Universidad de Chile y uno de los relegados, ese mundo compartía partido con los "guatones", pero configuraba un modo totalmente distinto de entender las formas, tareas y objetivos del activismo militante demócrata cristiano:

Frente a la consulta del 78 los que terminamos relegados no tenemos nada que ver con la estructura partidaria. Tomas Reyes, Belisario Velasco, Yunge, yo, los que nos mandan a Altiplano, Andrés Aylwin. (...) Eran dos mundos, completamente, dos mundos que conviven en una carcasa formal, pero eran dos mundos completamente distintos. (Juan Claudio Reyes)

Transcurrió un mes y medio hasta que los 12 DC relegados fueron autorizados a volver a la capital tras un decreto emitido el dos de marzo de 1978. A propósito de ello, Pinochet declaró: "Consideré que había llegado el momento de que estos caballeros habían meditado bastante y que había necesidad de que volvieran. Pero con la salvedad de que a la otra que me hagan se van a Pisagua, que queda más al sur, o a Chaitén".47

En abril de 1978 retornó al país Jaime Castillo Velasco, quien, en noviembre de ese año, junto a Máximo Pacheco y otras personalidades, firmó el acta fundacional de la Comisión Chilena de Derechos Humanos, organismo que se fijó como objetivo trabajar por la vigencia, respeto, protección y promoción de los derechos humanos establecidos por Naciones Unidas y otros organismos internacionales de los que Chile era miembro. En un proceso paralelo, estudiantes universitarios se coordinaron en torno a la promoción y defensa de los derechos humanos en la juventud, dando lugar a comisiones juveniles de derechos humanos en Valparaíso, Santiago y Concepción, las que confluyeron a principios de 1979 en la Comisión Nacional de Derechos Juveniles CODEJU, con acta fundacional fechada el 8 de febrero de 1979 y teniendo a Guillermo Yunge como presidente. ${ }^{48}$ La CODEJU desarrollaba una labor que implicaba elaboración de diagnósticos, denuncia y seguimiento de casos de violaciones a los derechos humanos (detenidos, exiliados, relegados, expulsados de la universidad, etc), asistencia a las víctimas en lo jurídico y en otras necesidades, generación de iniciativas de solidaridad con personas y grupos afectados, organización de reuniones y seminarios y, finalmente, un aspecto que la vinculaba a toda instancia organizada a nivel de los frentes sociales sectoriales, la labor de:"Estimular la organización independiente de jóvenes. Colaborar a la movilización juvenil por la defensa de sus derechos". 49

\footnotetext{
47 •*Relegados. Tiempo de ... *, Op cit, pp $14-15$.

48 Acta de fundación de CODEJU, 8 de febrero de 1979. En: Guillermo Yunge, “Derechos Humanos, Derechos Juveniles: La Comisión Nacional Pro-derechos Juveniles de Chile CODEJU*, Cuadernos ESIN, Instituto para un nuevo Chile, Santiago, 1980.

${ }^{49}$ Derechos Humanos... , op cit, pp 28.
} 
Si bien CODEJU fue una organización no gubernamental, plural y con presencia de voluntarios independientes y militantes de diferentes partidos de oposición, es claro que fueron militantes de la JDC, y militantes chascones de la JDC, los que la condujeron. Para los chascones, CODEJU fue también una plataforma desde la cual desarrollaron actividad política y se vincularon con frentes sociales como el movimiento estudiantil, el movimiento sindical y la izquierda partidista inserta en dichos frentes. Fue el refugio desde donde articularon su política de masas y de alianzas en un relativo paralelismo respecto a las direcciones de la JDC lideradas por presidentes "guatones" (Gutenberg Martínez 1974/1976, Jorge Pizarro - 1976/1979, Miguel Patricio Aylwin - 1979/1982, Miguel Salazar - 1982/1984), direcciones que, a los ojos del mundo chascón, no eran del todo legítimas, tanto por ausencia de procesos democráticos en su origen, o porque se acusaban vicios en los procesos de elección.

En general, el relato del mundo chascón es que durante todos esos años el grupo dirigido por Gutenberg Martínez controló la estructura y la mantuvo a como dé lugar, echando mano a las ventajas que daba manejar la "maquinaria partidaria" y su institucionalidad interna. El testimonio de Palma es reflejo de ese sentir en común por parte de los chascones, y más allá de los datos empíricos y de una verdad objetiva que no es nuestro afán develar, lo concreto es que esa subjetividad de verse perjudicado por una "maquinaria mañosa" o un "poder de facto", era otro elemento más que justificaba, para los chascones, la producción de una plataforma paralela de ejercicio partidario:

Gutenberg Martínez nombró como presidente de la JDC a Jorge Pizarro. Lo nombró directamente. Yo lo recuerdo exactamente así: un día Elías Sánchez me dice, "adivina quién es el nuevo presidente de la JDC... Ah, ¿nombraron a un nuevo presidente? Sí, y ¿quién es? El que menos te imagines tú. Yo le dije Jorge Pizarro. Ese es jajaja". Después hubo un proceso en el cual nosotros participamos de alguna manera, fuimos a la Junta en la cual se desarrolló ese proceso en que se eligió a Miguel Patricio Aylwin. Pero todo esto era totalmente monitoreado por Gutenberg Martínez en la sala de la JDC, estaban ahí en primera fila. Y el presidente del Tribunal Electoral fue Enzo Pistacchio. Resulta que nosotros discutimos el proceso, y nos retiramos. Entonces, en un gesto de unidad, como Secretario General asumió el presidente del Tribunal Electoral, o sea Pistacchio termina de Secretario General de la Juventud con Miguel Patricio Aylwin de presidente. Así de irregular el proceso. (Andrés Palma).

Así, mientras por un lado estaba la JDC proclive a la directiva, con cuadros universitarios como Gonzalo Duarte que solían aparecer en la prensa en tanto voz oficial de la JDC, por otro lado, estaban los líderes demócrata cristianos vinculados a CODEJU, encabezados por Guillermo Yunge y Gustavo Rayo, trabajando codo a codo con la izquierda y dedicados por completo a la articulación de movimientos sociales opositores: 
CODEJU quizás fue la primera experiencia concreta de concertación política juvenil. Desde un primer momento fue una expresión de acuerdo político entre nosotros y otras diversas juventudes. (Estaba) Jaime Insunza de las Juventudes Comunistas, de las Juventudes Socialistas estuvo Bernardo Echeverría. De hecho, en Valparaíso el presidente ni es Demócrata Cristiano, es Comunista, Jorge Maturana. (...) La experiencia se dio fundamentalmente en el mundo estudiantil universitario y el mundo sindical. El mundo sindical es donde actuaban personajes importantes nuestros, como María Rosas, como Manuel Bustos. (...) En lo poblacional me tocó estar en La Bandera, apoyamos ahí la primera toma que se hace bajo la dictadura. (...) La lucha por reconstruir el movimiento estudiantil universitario fue un eje fundamental. Por ejemplo, las Jornadas Solidarias Chiloé 81, las Jornadas por Universidad Libre. (...) El primer presidente de la CODEJU fue Guillermo Yunge. Yo fui seguramente a partir del año 79 y después de eso me siguió Felipe Sandoval. (Gustavo Rayo)

La CODEJU no solamente defendía y promovía los derechos humanos de los jóvenes, era un espacio de mesa política juvenil, de enfrentamiento contra la dictadura, de dialogo político. (José Sabat)

Desde esa perspectiva, no es extraño que Yerko Ljubetic, primer presidente de la Federación de Estudiantes de la Universidad de Chile FECH reconstruida en 1984, señalara a CODEJU como un espacio donde los jóvenes demócrata cristianos aprendieron a concertarse y trabajar junto con las juventudes de la izquierda, dando lugar a una idea fuerza persistente y característica de la identidad de los chascones: la unidad amplia del movimiento juvenil opositor.

(...) esta experiencia formativa nos sirvió para entender que una de las cuestiones que podemos aportar como nueva generación en la política nacional es, por ejemplo, la capacidad de abstraernos de nuestra filiación política cada vez que sea necesario para buscar entendimientos y reflexiones comunes con los otros. (...) Eso quedó grabado con los años de CODEJU. (Yerko Ljubetic) ${ }^{50}$

Coincidente con este proceso, 1979 fue el año en que se multiplicaron las instancias de convergencia opositora con miras a la rearticulación de un movimiento estudiantil orientado a redemocratizar los centros de alumnos y federaciones. En ese entonces, la fuerza más articulada y con mayor número de militantes en la izquierda eran las Juventudes Comunistas JJCC, muy por sobre los dos MAPU, la IC y las distintas facciones de un dividido Partido Socialista, de modo que gran parte del trabajo político colaborativo pasaba por el diálogo entre demócrata cristianos y comunistas, cuestión sumamente resistida por

50 Testimonio de Yerko Ljubetic en: Ricardo Brodsky compilador, Conversaciones con la FECH, Santiago, SESOC, 1988, pp 51. 
la hegemonía "guatona" en la dirigencia del PDC y la JDC. Para la JDC chascona, el trabajo conjunto con los comunistas no representaba una gran tensión, importando poco las consideraciones internacionales sobre las políticas soviéticas que argumentaban los guatones, y asumiéndose al PC como un partido que había sido particularmente fiel a los caminos democráticos e institucionales de la vía chilena al socialismo. No hay que olvidar también que, en ese contexto, durante la segunda mitad de los años 70, el PC todavía no ponía de manifiesto su Política de Rebelión Popular, la que a partir de 1980 aceptó todas las formas de lucha contra la dictadura, chocando con la idea de movilización no violenta que proponían los chascones.

Los chascones tenían una postura de mayor apertura hacia la acción conjunta con la izquierda y hablar en ese momento de izquierda era hablar del Partido Comunista, de las Juventudes Comunistas, porque el Partido Socialista estaba dividido, había una serie de grupos. La Izquierda Cristiana y el MAPU eran grupos pequeñitos, con muy poca militancia. (...) En las universidades se comenzó a producir esa convergencia con las Juventudes Comunistas y con otros sectores de izquierda respecto de las demandas del movimiento social. Obviamente, con los comunistas teníamos diferencias, pero teníamos la capacidad de ponernos de acuerdo. En ese momento, además, el PC no había tomado el giro que tomó en los 80, era bastante fácil. (Eduardo Saffirio)

Los que mostraban mayor coherencia orgánica eran los comunistas. Los comunistas sabían que un entendimiento con la Democracia Cristiana era lo que iba a permitir salir de la dictadura. (...) A nosotros nos vivían retando por esto de estar en acuerdos con el PC. (Rodolfo Fortunatti)

En el caso específico de la Universidad de Chile, durante 1978 las autoridades de la intervención dieron lugar a una institución de representación estudiantil federativa en reemplazo del Consejo Superior Estudiantil: la llamada Federación de Centros de Estudiantes de la Universidad de Chile (FECECH), cuya directiva se elegía en un complejo sistema de elecciones y designaciones. En 1979, se instauró la primera "elección de delegados de curso" dentro del sistema FECECH, proceso en el cual no se podían presentar alumnos sancionados ni inscribir listas con candidatos, a lo que se agregaba que la directiva de federación era elegida por los centros de alumnos oficialistas que habían sido designados el año anterior. Los años siguientes se mantuvieron los límites que impedían disputar el control a los herederos de las designaciones, pues no había elección universal, se elegían dos delegados por curso - primera y segunda mayoría - y cada directiva saliente de centro de alumnos contaba con valiosos votos para determinar la nueva directiva. En ese contexto, el activo opositor debatía en cada campus sobre la estrategia a seguir: si se rechazaban plenamente los mecanismos de FECECH en tanto espurios, o se tomaban estos y se hacían esfuerzos por desbancar al oficialismo según sus propias reglas, o bien, como idea complementaria de la anterior, se avanzaba en sumar representaciones para luego llamar a 
elecciones universales de algunos centros de alumnos por fuera de las lógicas del sistema FECECH. Para estas luchas y debates surgieron instancias de coordinación social y política militante del activo opositor, como el Comité Reorganizador del Movimiento Estudiantil CORREME (el juego de palabra del nombre resulta evidente), surgido en 1979 en el marco de las "Primeras Jornadas de Democratización de la Universidad" organizadas por la oposición y sus dos principales fuerzas militantes, la JDC y la JJCC. 51

Procesos similares se dieron en las otras universidades, teniendo todos ellos el horizonte común de la democratización de las instancias representativas del estudiantado. En todo lugar en donde la JDC chascona fue fuerte, la confluencia del activo opositor sumó, con más o menos visibilidad, a todas las militancias que iban desde el PC y el Movimiento de Izquierda Revolucionaria MIR hasta la JDC, siempre teniendo al CODEJU como organismo que apoyaba en la perspectiva de promover la organización estudiantil como un derecho.

Nos vamos a la Comisión de Derechos Juveniles, como ala juvenil de la Comisión Chilena de Derechos Humanos, encabezados por el líder, que venía de la FESES antigua, Guillermo Yunge, y ahí nos asilamos por decirlo así, en un contexto de alianza con el otro conjunto de las fuerzas opositoras, pero sobretodo los jóvenes del Partido Comunista, de las diferentes facciones socialistas, y empezamos un trabajo de articulación del movimiento estudiantil. De ahí surge el CORREME, el Comité Reorganizador del Movimiento Estudiantil, que me tocó presidir desde su creación pa delante hasta mi expulsión de la universidad el 79. (Juan Claudio Reyes)

Como lo señala Reyes en el testimonio recién citado, el activismo tenía riesgos y costos concretos para la vida académica de los estudiantes, los que iban desde suspensión temporal de clases hasta la expulsión de la universidad. En ese sentido, la ola creciente de movilizaciones que se desencadenó en 1979 coincidió también con el incremento de los sumarios y las sanciones. En la Universidad Católica, las movilizaciones que protagonizaron estudiantes de la carrera de teología en defensa de alumnos detenidos en manifestaciones del primero de mayo tuvieron como respuesta decenas de estudiantes suspendidos, incluidos dirigentes del centro de alumnos de la carrera. En la Universidad de Chile, durante la misma coyuntura, las manifestaciones de solidaridad con detenidos produjeron una treintena de alumnos sancionados, entre ellos los dirigentes de la JDC de la escuela de derecho Guillermo Pickering, Eduardo Saffirio y Gabriel Ascencio (suspendidos por tres meses), y el mencionado estudiante de sociología Juan Claudio Reyes, expulsado de la carrera. Este último fue orador en un acto con 600 estudiantes en el campus Macul, donde declaró: "La universidad es para estudiar, pero también para formar profesionales íntegros,

\footnotetext{
51 Ricardo Brodsky y Ramiro Pizarro, "'La constitución del movimiento estudiantil como proceso de aprendizaje político“, en Irene Agurto, Manuel Canales, Gonzalo De la Maza, Juventud chilena. Razones y subversiones, Santiago, Eco, Folico, Sepade, 1985.
} 
dispuestos a entregar su sacrificio, incluso su carrera universitaria, para ponerlo al servicio de Chile y su pueblo. Sin justicia y libertad bien sabemos, compañeros, que no hay universidad"52

Los años 1980, 1981, 1982 y 1983 estuvieron determinados por eventos de connotación nacional que fueron claves en la configuración de identidades opositoras del estudiantado. En 1980 la DC, ya visiblemente opositora, hablaba de la necesidad de una Asamblea Constituyente, de una alternativa corta de transición a la democracia, y denunciaba las condicionantes autoritarias del plebiscito para aprobar la Constitución, proceso que calificaba de ilegítimo, fraudulento e instrumento para perpetuar la autocracia. El ex presidente Frei fue entonces la voz pública protagónica de este rechazo a la nueva institucionalidad constitucional y al mecanismo plebiscitario, siendo un verdadero hito aglutinador de la oposición su discurso en el teatro Caupolícán en el que dijo reiteradas veces que el plebiscito fijado para el 11 de septiembre de 1980 "no es válido“.53 Tras el anuncio de la victoria oficialista, en el mes de octubre, Andrés Zaldivar, presidente del PDC, fue impedido de reingresar al país, iniciando un exilio que se extendió hasta $1983 .{ }^{54}$ En enero de 1982, Eduardo Frei Montalva moría en lo que décadas más tarde quedaría expuesto como otro asesinato de la dictadura. Tras ese suceso, un consenso partidario entregó la presidencia del PDC a un hombre proclive al entendimiento con parte de la izquierda y al fortalecimiento de la movilización social antidictatorial: Gabriel Valdés.

En 1981, la marcha de las modernizaciones neoliberales tuvo a la educación superior como uno de sus objetivos. Se promulgó la Ley General de Universidades que consagró la idea del autofinanciamiento por vía del endeudamiento del estudiantado, la apertura a una extensión de la oferta universitaria mediante instituciones privadas y la fragmentación de las Universidades públicas estatales nacionales como la Universidad de Chile y la Universidad Técnica. El activo opositor recibió la ley junto con una represión a todo nivel: expulsiones, relegamientos, detenciones, que marcaron un corto repliegue del movimiento democratizador.

En definitiva, en el PDC post plebiscito de 1980 cobró fuerza la idea de centrar esfuerzos en la "movilización" 55 a nivel social como modo de enfrentar la dictadura y generar un camino a la democracia, cuestión que la juventud chascona recogió como objetivo primordial del momento. En palabras de Guillermo Yunge: "El sentido de la lucha y la capacidad creciente de ir formulando una alternativa consensual, reafirmadas frente al pseudo plebiscito, dan al Partido un papel importante en la perspectiva de la movilización popular y la configuración del proyecto democrático nacional".56 La crisis económica en 1982 y la emergencia de las jornadas de protesta nacional en 1983, definieron luego la extensión y tenor de la movilización antidictatorial en las ciudades: la dinámica de la protesta que empezaba en el centro con los estudiantes y terminaba en la periferia con los pobladores.

En asambleas y barricadas, los jóvenes demócrata cristianos compartieron con los jóvenes de la izquierda, dando lugar a procesos identitarios en común. En el movimiento

\footnotetext{
52 "El apoyo a sancionados", Revista Hoy, Santiago 23 al 29 de mayo de 1979, pp 15.

53 Eduardo Frei, "Discurso de Eduardo Frei pronunciado el 27 de agosto de 1980 en el Teatro Caupolícán”, Documentación sobre observaciones y alternativas al plebiscito, Archivo Patricio Aylwin, pp 37.

54 “Caso Zaldivar. Preguntas de un exiliado“, Revista Hoy, Santiago, 5 al 11 de noviembre de 1980, pp 12-13.

55 Aylwin, El reencuentro..., pp 188.

56 Guillermo Yunge, "Esperanza en el cambio“, Revista Análisis, Santiago, noviembre de 1980, pp 14.
} 
estudiantil, esta confluencia se expresó en la recomposición de federaciones universitarias elegidas por voto universal, donde izquierda y DC también compartieron la dirección de tales organismos representativos. La disputa interna en la DC pasará del debate sobre la pertinencia de la movilización pública antidictatorial, al rol y carácter de esa movilización. Siendo un contexto más favorable para las ideas fuerzas del activo chascón, las tensiones perduraron, particularmente en el modo de definir la vinculación con el movimiento popular, con el movimiento estudiantil, y con la diversa izquierda ahí presente.

Hacia mitad de los años ochenta, la identidad chascona seguía articulando un agrupamiento de corriente visible y organizada en la JDC, estableciendo vínculos permanentes con los frentes sociales más allá del estudiantil, particularmente el sindical, teniendo como referentes a los cuadros adultos del progresismo DC y cultivando aún el carácter rebelde con la dirección partidista:

El mundo nuestro tenía una pata en el mundo social bien fuerte, se juntaba esto con el mundo sindical, con el mundo estudiantil. Ahí tení al Andrés Rengifo, al Yerko, teníamos un peso potente en el ámbito social. (...) Había movilizaciones sociales que la Democracia Cristina no apoyaba y nosotros igual apoyábamos, de hecho, el Tribunal de Disciplina nos pasaba llamando a cada rato porque no obedecíamos instrucciones. (...) Siempre funcionábamos con una dinámica propia chascona, o sea, teníamos reuniones, asambleas, tomábamos decisiones y conversábamos según las apuestas a nivel nacional, recorríamos el país a nivel nacional también. Nos apoyaban los viejos chascones, estamos hablando de Claudio Huepe, de Mariano Ruiz Esquide, de la María Rosas, de Manuel Bustos. (Cecilia Valdés)

\section{Federaciones estudiantiles, política nacional e interna JDC. 1983 - 1989}

En el año 1983, el encauzamiento opositor de la Democracia Cristiana hacia la movilización antidicatorial tiene repercusiones en su política de alianzas. La conducción de Gabriel Valdés establece mayores nexos con el espectro socialista moderado e ideológicamente afín a las ideas de lo que ya se conocía como "renovación socialista”, y mantiene la distancia con el Partido Comunista que, en el marco de su Política de Rebelión Popular de Masas, había dado forma a su apuesta insurreccional al crear en 1983 el Frente Patriótico Manuel Rodríguez. En el mes de marzo, un grupo de militantes de la DC, otros identificados con una derecha no pinochetista, más corrientes socialistas y del partido radical, firmaron el "Manifiesto Democrático" que proponía un "acuerdo nacional" para el retorno de la democracia. De los firmantes, surgió luego la Alianza Democrática (AD), coalición que reunió a la DC, al Partido Liberal, al Partido Radical PR y al PS de la renovación dirigido por Ricardo Núñez. La AD intentó desarrollar un diálogo con el régimen por vía del ministro del Interior Sergio Onofre Jarpa, discutiendo con él puntos como el reconocimiento de los partidos, la represión y el exilio, hasta que en septiembre de 
1983 tal diálogo fue desechado por el propio Pinochet. 57 Paralelamente, el PC, el PS Almeyda y el MIR, como una forma de contrarrestar la opción dialogante y moderada de la $\mathrm{AD}$, formaron el Movimiento Democrático Popular (MDP), que se proponía intensificar la movilización rupturista con elementos insurreccionales como camino para provocar el derrocamiento del gobierno.

Mientras la oposición se agrupaba, los universitarios opositores lograron desbancar a las representaciones gremiales designadas bajo el modelo de la intervención e implementaron elecciones democráticas que significaron el resurgimiento de las federaciones a lo largo de todo el territorio nacional. En la Universidad de Chile, durante la reconstrucción de la FECH en 1984 los partidos políticos opositores no replicaron la distinción entre AD y MDP, y fueron unidos en una sola lista. Esa lista obtuvo 9.205 votos contra 2.129 del gobiernista Frente Universitario. Dentro del bloque ganador los votos se distribuyeron: 4.385 para Yerko Ljubetic de la Democracia Cristiana (DC), 2.333 para Gonzalo Rovira de las Juventudes Comunistas (JJCC), 1.331 para Ricardo Brodsky del Bloque Socialista (convergencia de diversos sectores de la "renovación socialista"), y 774 para Jaime Andrade de la Juventud Socialista adscrita al MDP y a la fracción del Partido Socialista dirigida por Clodomiro Almeyda. ${ }^{58}$ Ljubetic ocupó la presidencia y Rovira la vicepresidencia, con lo que un comunista aparecía como el segundo cargo de importancia y trabajando en acuerdo con el representante de la JDC.

Los chascones, absolutamente hegemónicos en la DC de la Universidad de Chile, optaron por la unidad a contrapelo de orientaciones explícitas de la dirección del partido en torno a que no se debían hacer alianzas con los comunistas ni el MDP en los frentes sociales. Como lo recuerda Ljubetic, estando Gabriel Valdés fuera de Chile, las circunstancias hicieron que fuera el vicepresidente del partido, Patricio Aylwin, quien infructuosamente tratara personalmente de persuadir a la JDC de la $\mathrm{U}$ de Chile de acatar una orden relativa a la política de alianzas:

La Democracia Cristiana, la directiva, decide prohibir todo tipo de alianzas electorales con los comunistas en cualquier parte, pensando particularmente en la FECH que ya comenzaba a ser noticia. Entonces nosotros dijimos que no, que éramos un movimiento social, que, si bien éramos militantes, nos debíamos a un movimiento social, y por tanto ahí no cabían los vetos ni las divisiones que había en el mundo estrictamente de los partidos. Valdés era el presidente del partido, pero estaba fuera de Chile. Llego Aylwin a un local que teníamos, a una asamblea de $300-400$ militantes, y Aylwin que tuvo coraje, fue a decirnos en nuestra cara que no. Uno de los nuestros se pegó un discurso muy sentido, se apagan las luces por unos minutos, y todo el mundo empieza a gritarle a Aylwin todo tipo de groserías y se prende la Luz y Aylwin

\footnotetext{
57 A estas jornadas de diálogo no asistieron representantes socialistas de la AD que rechazaron sentarse a la mesa con un gobierno que había diezmado a su partido.

58 García, Isla, Toro, Op cit, pp 184.
} 
dice: está clara cuál es su opinión que les vaya muy bien y se fue. (Yerko Ljubetic)

Ljubetic y los chascones de la Universidad de Chile presentaron la unidad en la FECH como una señal potente emanada desde el movimiento social en general, y desde el movimiento estudiantil en particular, en torno a que la oposición debía operar sin ningún tipo de exclusiones. Todo ello se sintetizaba en dos ideas fuerza: "unidad en la base" y "autonomía del movimiento social respecto a los partidos". ${ }^{59}$ Así lo planteó el propio Yerko Ljubetic en su discurso tras el triunfo en la FECH: "En medio de un dramático espectáculo de divisiones, y querellas incomprensibles para quienes están viviendo cotidianamente los dramas del hambre, la miseria, la represión, la humillación, ¿Qué mejor noticia que la que trae la FECH?: la unidad es posible." 60

Mientras la JDC universitaria con hegemonía chascona ganaba conducciones de federaciones, sus coordinaciones estudiantiles fueron la base de alianzas para disputar la directiva JDC a los guatones en las elecciones internas de 1984. Hay acá un aspecto relevante, que es que "lo chascón" no era percibido de igual manera en los campos universitarios que a nivel nacional. A nivel universitario, "los chascones" articulaban una corriente opositora a "los guatones", pero en un escenario en donde había otras expresiones que no se posicionaban ni en uno ni en otro sector. Ese era el caso de grupos que recibieron diferentes denominaciones, algunas incluso como nomenclaturas locales sólo presentes en espacios universitarios específicos. En general, las denominaciones que más se repiten para esos grupos eran las categorías de "terceristas" e "iluminados", y tenían liderazgos como el de Eduardo Saffirio en la Universidad de Chile, Tomás Joselyn Holt en la Universidad Católica y Sergio Micco en la Universidad de Concepción (primero señalado como chascón y luego como iluminado). ${ }^{61}$ Es decir, si bien el grueso de esas corrientes tenían posiciones que en la política universitaria podían dar lugar a distinciones con "lo chascón", esas mismas distinciones perdían nitidez a una escala nacional, donde la convergencia de algunos de estos grupos en alianza contra los guatones, provocaba que la nomenclatura "chascón" se extendiera a sectores que en la universidad no eran vistos como tales. Como lo describe Burotto en relación con los "iluminados": "En la juventud se va a producir una huevá obvia, todos estos grupos van a ser la izquierda de la juventud, cuando entraron a enfrentar la estructura territorial, $y$, de hecho, van a hacer alianzas con nosotros (los chascones) ".

Así, tales corrientes confluyeron para ganar, primero, las coordinaciones universitarias de la JDC, como la Democracia Cristiana Universitaria de la Universidad de Chile DCU y las candidaturas a las federaciones, y luego, para disputar la elección de directiva nacional de la JDC en 1984. Ese año, los chascones tenían la intención de llevar como candidato a la presidencia a Juan Claudio Reyes, pero los "iluminados" negociaron

\footnotetext{
${ }^{59}$ La idea de autonomía del movimiento social respecto a los partidos, y en tanto principio asociado a la "unidad en la base", fue constante en los discursos provenientes de la JDC chascona. Incluso ad-portas de 1988, cuando resultaba evidente el aislamiento de los comunistas. Ver, por ejemplo: Entrevista a Yerko Ljubetic: "Nuestros acuerdos no serán pasados a llevar", Revista Análisis, Santiago, 2 de noviembre de 1987, pp 30 - 32.

${ }^{60}$ En "Discurso de constitución de la FECH", 25 de octubre de 1984. En Agurto y otros, op cit, pp 159- 160.

61 En el caso de los Iluminados, también en el partido adulto había dirigentes que se les señalaba con ese apelativo, como Genaro Arriagada, Sergio Molina y Eugenio Ortega, entre otros.
} 
una alianza con la condición de que el candidato fuera un nombre que les incomodara menos: Andrés Palma.

Palma representó la tesis de la convergencia amplia opositora en la movilización social y en las federaciones estudiantiles, lo que implicaba manifestar disposición a entenderse con la izquierda y el PC, cuestión que estaba en radical oposición a la candidatura guatona de Miguel Salazar, quien insistía en definirse como anticomunista. Al respecto, hoy recuerda Palma: "Proponíamos una lista unitaria, en todas partes. La unidad en la movilización. Y en las protestas avalábamos la barricada y avalábamos que se juntara todo el mundo y no decir nosotros vamos sin estos otros. Los guatones, Salazar, seguían con el anticomunismo, pero no tenían caja de resonancia". Sin embargo, esa disposición se matizaba al señalar de modo rotundo que la opción de la JDC chascona era la movilización pacífica, distante de la apuesta comunista de todas las formas de lucha. En síntesis, se hablaba de priorizar por la unidad en lo que se asumía como prioritario, que era la movilización antidictatorial y democratizadora, pero manteniendo de modo explícito las diferencias en torno a las formas de lucha, y presentando la lucha pacífica y la desobediencia civil como elementos distintivos de la JDC en el campo opositor. ${ }^{62}$

En ese último sentido, entre 1983 y 1985 los dirigentes chascones llegaron a plantear que era posible, desde los movimientos sociales, llegar a ciertos consensos cotidianos en relación a las formas de lucha: por un lado, procurar que los elementos de cierta violencia callejera que se promovían desde la izquierda no atentaran contra la masividad de las manifestaciones y, por otro, aceptar desde la militancia JDC que algunos de esos métodos de lucha callejera (como las barricadas) podían servir, contextualmente, para limitar la labor represiva de la policía. Así lo explicitó en su momento Yerko Ljubetic:

(...) hemos definido criterios, como por ejemplo los de oportunidad, masividad y eficiencia de los medios que empleamos (...) hemos podido construir una estrategia de desobediencia estudiantil, de ingobernabilidad universitaria y de movilización masiva, oportuna y eficaz. Esta es de consenso y ha permitido cosas como que haya estudiantes demócrata cristianos haciendo barricadas en la calle, para impedir la brutal acción de carabineros. O que haya dirigentes del MDP increpando a algunos de sus militantes y obligándolos a entrar a la Facultad porque la barricada no es - en ese momento- la forma eficaz, masiva y oportuna de actuar. 63

Finalmente, en la elección de la JDC de 1984 Palma empató con Miguel Salazar, en el marco de un sistema indirecto de votación, y se decidió "salomónicamente" que Salazar asumiera el primer año y Palma el segundo. Dos años después, los chascones y sus aliados obtuvieron cómodamente el triunfo de su candidato Felipe Sandoval.

\footnotetext{
62 Ver entrevista a Andrés Palma por Patricio Acevedo: "La otra cara de la JDC", Revista Análisis, Santiago, 22 de mayo de 1984, pp 42 - 43.

63 Entrevista a Yerko Ljubetic: "Unidad y movilización es la fórmula imbatible“, Revista Análisis, Santiago, 15 de octubre de 1985.
} 
La hegemonía universitaria de las tesis chasconas de unidad y movilización no impidió, sin embargo, que emergieran una serie de discusiones en la JDC a propósito de la política de alianzas. Porque si en 1984 el lema era la unidad sin exclusiones, una serie de tensiones con la política de los comunistas matizaron esa primera intención. De hecho, en la Universidad de Chile, una lista FECH unitaria de toda la oposición sólo se dio en 1984. En 1985 dicha unidad se rompió. Ese año, en agosto, se había firmado el "Acuerdo Nacional"64, y este se transformó en el punto de la discordia para una lista conjunta. En la DCU, una corriente denominada "los pelados" planteó que el Acuerdo Nacional debía ser, junto con la movilización antidictatorial, el eje de la lista al ejecutivo $\mathrm{FECH}$ en las elecciones de fines octubre. Este grupo, en una votación interna para definir al candidato DC que sucediera a Ljubetic, apoyó al "chascón" Humberto Burotto, que enfrentaba a otro "chascón", Ángel Domper. Mientras el primero se acercó a las posturas de "los pelados", el segundo siguió la línea de Ljúbetic en el sentido de rechazar rotundamente la idea de condicionar la unidad opositora. 65 Triunfando Burotto y las posiciones de quienes lo apoyaban ("chascones pelados"), se impusieron también las mencionadas condicionantes para una lista unitaria. La DCU pidió a las fuerzas universitarias del MDP, particularmente a los comunistas, aceptar el Acuerdo Nacional como plataforma de una nueva directiva de federación, cuestión que, si bien terminó imposibilitando que se reeditara la unidad electoral opositora del año anterior, no impidió que luego se materializara una fórmula de integración en la directiva de las candidaturas más votadas, lo que derivó en una mesa con la presidencia DC de Burotto y la vicepresidencia JJCC de Gonzalo Rovira. ${ }^{66}$

Hacia 1986, los éxitos relativos de la movilización social coincidieron también con su más evidente desgaste y una represión feroz. Esta última golpeó directamente a la JDC cuando fue encontrado sin vida el cuerpo de uno de sus dirigentes, el secretario de la Federación estudiantil de la Universidad de Santiago USACH Mario Martínez, y todas las sospechas indicaron que se trataba de un nuevo asesinato perpetrado por agentes de la dictadura. 67

En la política universitaria, las tensiones entre la oposición y los comunistas siguieron en aumento, no sólo por la DC sino también por parte de la izquierda, particularmente en relación con la centralidad que los comunistas daban a los elementos insurreccionales, o de sublevación, presentes en la protesta callejera (corte de calles con fuego, enfrentamientos a pedradas con la policía, uso de cóctel molotov). ${ }^{68}$ Aun así, todo el

\footnotetext{
64 A comienzos de 1985 el Cardenal de la Iglesia de Santiago Juan Francisco Fresno, buscó retomar el diálogo interrumpido entre la AD y el gobierno, llamando a diversos sectores políticos de centro, izquierda y derecha a suscribir un "Acuerdo Nacional para la Transición a la Plena Democracia". La iniciativa logró reunir por la izquierda al PS renovado y a la IC - el MAPU pidió luego también integrarse - , por el centro a la DC, y por la derecha a los liberales y al Movimiento Unión Nacional (MUN). El documento redactado planteaba medidas de apertura política para iniciar una transición a la democracia y un plebiscito para reformar la Constitución. El MDP declaró que, si bien valoraba algunos aspectos establecidos por el "Acuerdo", no lo suscribía porque no se exigía la renuncia a Pinochet y, a su juicio, se legitimaba la constitución de 1980.

65 Ver: Entrevista a Ángel Domper, “Los políticos nos deben estos doce años”, Revista Análisis, Santiago, 12 de noviembre de 1985.

66 Ver: "Itinerario de un desacuerdo", Revista Apsi, Santiago, 21 de octubre de 1985.

67 Ver: "U de Santiago: Miedo en las aulas", Revista Hoy, Santiago, 18 de agosto de 1986, pp 14 - 16.

68 Fue constante el debate sobre la violencia, que para los comunistas significaba preparar el camino a la sublevación nacional, pero para la DC y amplios sectores socialistas representaba también un factor que atentaba
} 
esfuerzo de unidad social opositora expresado en la Asamblea de la Civilidad ${ }^{9}$ llegó a su punto más alto en el paro del 2 y 3 de julio que, si bien fue un hito, estuvo lejos de sus pretensiones de forzar la caída de Pinochet. La represión brutal simbolizada en dos jóvenes quemados vivos por una patrulla militar, las decenas de dirigentes presos, el simple cansancio, el miedo y el rechazo de amplios sectores sociales a las expresiones más descontroladas de la violencia, hicieron que ese paro fuese uno de los últimos grandes eventos de aquella "unidad y movilización en la base" defendida por los chascones. Burotto recuerda al respecto: "El 86, colapsó la Asamblea de la Civilidad producto del agotamiento de las masas populares. (...) Estábamos empezando a tener cierta involución, cierto rechazo también". Los posteriores eventos del hallazgo de armas en Carrizal y el frustrado tiranicidio del FPMR remecieron al MDP y determinaron la derrota de las apuestas por el derrocamiento de Pinochet por vía insurreccional, cuestión que marcó un giro definitivo del PS Almeyda hacia el bloque DC- renovación socialista, produciendo el aislamiento político de los comunistas. La entrada clandestina al país de Clodomiro Almeyda y su entrega a los tribunales a principios de 1987 fue parte de la puesta en marcha del viraje socialista ya que, a partir de entonces, este líder fue activo en establecer conversaciones tanto con los dirigentes de su partido (PS Almeyda) como con los líderes de "la renovación" (PS Núñez) y la Democracia Cristiana, en la perspectiva de definir estrategias para una salida jurídico-política. ${ }^{70}$

A inicios de agosto de 1987, la Junta Nacional de la DC eligió presidente del partido a Patricio Aylwin, quien obtuvo el 55\% de los votos venciendo al candidato de los chascones Ricardo Hormazábal y a Arturo Frei. La JDC chascona, que persistía en su lema "movilización social y concertación politica", y que consideraba la institucionalidad pinochetista como "una camisa de fuerzas que solamente favorece la continuidad de Pinochet 71 , había hecho grandes esfuerzos por convencer a Gabriel Valdés de disputar esa elección, pero el dirigente emblema de las movilizaciones antidictatoriales de los 80 se negó. Según los testimonios de los ex jóvenes chascones, Valdés habría considerado que un alejamiento de la dirección partidaria lo perfilaba de mejor manera para encabezar un proyecto de gobierno posdictatorial, es decir, para una futura candidatura presidencial. El temor chascón, por el contrario, era que un retorno protagónico de Aylwin podía catapultar a este último para encabezar un primer gobierno democrático.

Los iluminados convencen a Valdés de que él tenía que ser un factótum por sobre todos y que el rol de presidente del partido dificultaba aquello, y por lo tanto él ni debía postular a la reelección de la Democracia Cristiana. Y entonces, el grupo más progre levanta la candidatura de Ricardo Hormazábal, los guatones a Juan

\footnotetext{
contra la masividad de las manifestaciones. García, Isla, Toro, Los muchachos..., pp 246. Muñoz Tamayo, Generaciones..., pp 200.

${ }^{69}$ El 26 de abril de 1986 las federaciones universitarias agrupadas en CONFECH, más otras 17 organizaciones sociales, firmaron un petitorio de reivindicaciones sectoriales y globales que incluían la vuelta de la democracia. La red de organizaciones se denominó “Asamblea de la Civilidad” y el petitorio, "La Demanda de Chile".

70 Víctor Muñoz Tamayo, "Militancia, facciones y juventud en el Partido Socialista - Almeyda. (1979-1990) “, Revista Izquierdas 37, USACH IDEA, Santiago, 2017.

71 Ver entrevista: “Felipe Sandoval, virtual presidente de la JDC: el 70\% con la tesis progresista", Revista Análisis, Santiago, 13 de julio de 1987, pp 6-8.
} 
Hamilton y los outsider, Arturo Frei. Esto se decidía en Junta, una Junta de trecientos y tantos miembros, o sea, era perfectamente claro saber cómo iban a ser los resultados. Avanzando el proceso, Hormazábal le ganaba a Hamilton, claramente. Los guatones entonces van a buscar a Aylwin. Le hacen el planteamiento de que aquí la DC se va ir a la izquierda, que esto va a ser el caos, y que una cierta fórmula pactada de salida al conflicto institucional democrático no iba a ser posible porque nosotros íbamos a radicalizar la protesta. $\mathrm{Y}$ convencen a Aylwin de que reemplace como candidato a Juan Hamilton. Volvemos a hacer las cuentas y Aylwin recuperaba lo que no captaba Hamilton, y Aylwin le ganaba a Hormazábal. Y entonces se produce una reunión dramática en la casa de Valdés. Hormazábal no tiene ningún problema en reasignar la candidatura, pero que asuma Valdés. Valdés le ganaba a Aylwin sin problemas y Valdés no estuvo dispuesto, convencido de que él tenía que estar por sobre el bien y el mal. Aylwin, una bestia política, olió la sangre y no la soltó más, ganó la presidencia del Partido en esa Junta en Punta de Tralca y de ahí en adelante la historia la conoces. Esa noche en la casa de Valdés él pierde la presidencia de la república. (Juan Claudio Reyes).

Valdés decide no ir de candidato a presidente del partido. (...) No fue candidato porque él quería ser candidato a presidente. Yo lo fui a ver a la casa pa tratar de convencerlo, fuimos a Chachagua a verlo, al viejo no le entró en el mate, el creía que tenía un derecho que el partido se lo iba a reconocer y que si él se metía en la cosa chica iba a perder apoyo. Y le creció Aylwin. (Humberto Burotto)

El triunfo de Aylwin implicó también el triunfo de su propuesta de iniciar la inscripción de la DC en el marco de la nueva ley de partidos. Los chascones rechazaban esta idea, 72 tanto porque consideraban que ello era avalar la institucionalidad pinochetista con todas sus restricciones a los partidos ${ }^{73}$ y elementos de continuidad autoritaria, como porque entendían que ello podía dificultar la convergencia opositora. ${ }^{74} \mathrm{La}$ propuesta era continuar la presión, ahora con el objetivo de forzar elecciones libres, sin aceptar el mecanismo del plebiscito en 1988 y elecciones eventualmente en 1989. De hecho, el propio Hormazábal declaraba que llegar a pensar en ganar el plebiscito en 1988 era "un sueño de ficción" y que "no se puede creer en las reglas del juego de Pinochet"75. Con Aylwin al mando, la apuesta por las elecciones libres logró mantener cohesionada a la DC, pero dio un rápido paso a una

\footnotetext{
72 Ibid.

73 Por ejemplo, la ley establecía que quienes ocuparan cargos de representatividad social no podían ser militantes de partidos. Ver: “Inscripción: la polémica se inicia“, Revista Análisis, Santiago, 28 de septiembre de 1987.

74 Ver Entrevista Ricardo Hormazábal: rechazo categórico a la ley de partidos, Revista Análisis, Santiago, 10 de marzo de 1987, pp 30 - 32.

75 Entrevista a Ricardo Hormazábal: “ ¡No le crean nada a Pinochet! ’. Revista Análisis, Santiago, 6 de junio de 1987.
} 
movilización electoral por ganar el plebiscito, cuestión a la que los chascones, en el nuevo contexto, cedieron.

En este nuevo ciclo, uno de los pocos eventos de movilización social juvenil importante en el que participa la JDC fue el paro contra la rectoría de José Luis Federici en la Universidad de Chile, entre fines de agosto y fines de octubre de 1987, y que terminó con la renuncia del rector. Atrás había quedado el intento de provocar la caída de la dictadura desde la movilización social en todos los frentes y desde coordinaciones sociales nacionales. Como recalca Burotto:

La última FECH de la movilización social abierta contra la dictadura es la del 86. Nosotros construimos la Asamblea de la Civilidad. La del 87 es una FECH que enfrenta el problema universitario. La FECH Quintana-Tohá 76 es claramente asumir que había un desgaste tal de la movilización social que uno de los pocos sectores donde todavía quedaba energía y posibilidad de hacer movilización social era en las universidades. (Humberto Burotto)

De ahí en adelante, todo el activismo juvenil opositor tendrá el sello predominante de la movilización electoral: concentraciones por el No a Pinochet, brigadas para enseñar a votar, jornadas de preparación de apoderados de mesa. En marzo de 1988 el PDC se inscribió como partido político. Una semana más tarde, socialistas, radicales y liberales inscribieron el Partido por la Democracia. Yerko Ljubetic oficiaba de Coordinador General del Movimiento Juvenil por el No, que agrupaba a 13 juventudes políticas opositoras.77

Tras el triunfo opositor en el plebiscito del 5 de octubre de 1988, la definición del candidato presidencial tuvo, como lo anticipaban los temores chascones, a Aylwin como protagonista. Se hizo una elección para definir al candidato de la DC entre tres nombres: Patricio Aylwin, Gabriel Valdés y el hijo del presidente Eduardo Frei Montalva: Eduardo Frei Ruiz Tagle. La JDC chascona no tuvo una sola postura. Unos, como Humberto Burotto, apoyaron a Valdés. Otros, la mayoría, todavía decepcionados con este último por no haber disputado en su momento la presidencia del partido, optaron por darle la espalda y apoyar a Eduardo Frei Ruiz Tagle como carta presidencial que pudiera evitar un gobierno de Aylwin. Pese a la limitada trayectoria política de Frei hijo, los jóvenes chascones vieron en él una pragmática alternativa para asegurar un triunfo en la presidencial (indudablemente el apellido Frei atraía electores) y una oportunidad de renovación que podría generar una correlación de fuerzas más óptima para los grupos progresistas de la Democracia Cristiana.

Los chascones de la DC se dividen entre Valdés y Frei. Hormazábal está con Frei, yo estoy con Frei, Huepe se queda con Valdés. Que no tenía ninguna posibilidad, porque después de su estupidez de no

\footnotetext{
76 Se refiere a Germán Quintana (JDC) y Carolina Tohá (socialista de la renovación), presidente y vicepresidentes de la FECH durante el paro contra Federici en 1987.

77 Ver: "Entrevista a Yerko Ljubetic, Coordinador del Movimiento Juvenil por el No", Revista Apsi, 6 de junio de 1988, pp $21-23$.
} 
seguir en la presidencia de la DC el mundo chascón termina bastante desencantado. (Juan Claudio Reyes)

Se produjo una ruptura decidida también por chascones favorables a la candidatura de Eduardo Ruiz Tagle, porque se pensaba que Eduardo Frei Ruiz Tagle, por su juventud, podía generar un cambio. Estuve con Frei porque tomamos una decisión colectiva, nos reunimos en el Colegio de Profesores, en una de las salas y ahí estaban presentes Ricardo Hormazábal, Andrés Palma, Flavio Cortés, Gustavo Rayo, en fin, es decir los jóvenes que podrían ser identificados como chascones, y en ese momento tomamos la decisión de respaldar la candidatura de Eduardo Frei Ruiz-Tagle. (Rodolfo Fortunatti)

Aylwin ganó finalmente la nominación que se oficializó en febrero de 1989, pero en medio de acusaciones que hablaban de manipulación del padrón electoral de los militantes en favor de su candidatura, situación que la prensa denominó “el carmengate" 78 . Pronto Aylwin concitó el apoyo de los otros partidos, incluso un temprano apoyo del PS Almeyda. Se cerraba así un proceso de unificación, realineamiento y redefinición de la oposición; que comenzó con el nacimiento de la Concertación de Partidos por el No en febrero de 1988, siguió con la movilización político electoral hasta el triunfo de octubre, y terminó con Aylwin como candidato de la Concertación de Partidos por la Democracia, alianza amplia entre la DC, partidos opositores menores y el conjunto de las fuerzas de izquierda no comunista.

El consuelo chascón fue insistir en un diagnóstico positivo: "perdimos el candidato, pero ganamos la tesis", es decir, consideraron que se había logrado un proyecto de gobierno conjunto con parte de la izquierda, desterrando definitivamente la vieja noción del camino propio y la más reciente propuesta de alianza más pequeña y excluyente conocida como "coalición chica", que apostaba restrictivamente por las fuerzas de la AD, eventualmente incorporando al PS Núñez, pero en ningún caso al PS Almeyda. ${ }^{79}$ "Perdimos el candidato y ganamos la tesis" 80 fue, no obstante, el diagnóstico referido estrictamente al acuerdo político de lo que Aylwin llamó “el reencuentro de los demócratas“, mientras que aquellas otras nociones relativas al proyecto integral de sociedad, al modelo económico y a cómo enfrentar la llamada deuda social que dejaba la dictadura en el contexto de límites estructurales de la transición y sus enclaves autoritarios ${ }^{81}$, quedaba como problemática pendiente de la posdictadura.

\footnotetext{
78 Ver: “Democracia Cristiana a río revuelto. Polémica por irregularidades denunciadas en la elección”, Revista Hoy, Santiago,6 de diciembre de 1988, pp 6 - 9. Y: “Elecciones internas. Lo que pasó en a DC", Revista Apsi, Santiago, 5 de diciembre de 1988, pp $4-7$.

79 Boeninger, Gobernabilidad, lecciones de..., pp 402.

80 Esta idea fuerza es explicitada por Renán Fuentealba en entrevista: “Aylwin adoptó todas las tesis de Gabriel Valdés", Revista Análisis, Santiago, 22 de mayo de 1989.

81 Por enclaves autoritarios se entiende: la existencia de los "senadores designados" y "senadores vitalicios" (que incluyeron al propio Pinochet en 1998 en tanto expresidente), la inamovilidad de las comandancias en jefe de las fuerzas armadas (que implicó tener al ex dictador dirigiendo el ejército hasta 1998) y las atribuciones y carácter del Consejo de Seguridad Nacional (y su influencia en la composición del Tribunal Constitucional). El sistema
} 
Desde entonces, los que habían sido identificados como "guatones“ de la JDC y el partido durante dictadura, persistieron básicamente como poderosa red de cuadros que "aceitaron" eficientemente una "maquinaria" de ordenamiento y distribución de poder. Los "chascones" y la generación juvenil chascona, en cambio, sin los referentes contextuales en que se forjó su identidad, tendieron a desaparecer como subgrupo identificable, estable y organizado.

- A modo de conclusiones. La transición a la democracia y el devenir chascón.

La salida transicional, expresada en el plebiscito de 1988 y las elecciones de 1989, terminó por cambiar completamente las condicionantes y referencias que habían dado razón de ser a la identidad chascona, y que se estructuraban a partir de su doble apuesta por la unidad opositora amplia y por la movilización social como camino prioritario para una salida de la dictadura. Por lo mismo, lo chascón no tuvo continuidad como corriente visible, cohesionada, con proyecto definido y permanencia en el tiempo, sino más bien como referencia identitaria asociada a cierta mirada "de izquierda", pero demasiado vaga y dispersa como para disputar protagonismo en las luchas por la organización y distribución del poder en la DC. En relación con esto, se enumeran las siguientes conclusiones:

1.- El nacimiento de la Concertación de Partidos por la Democracia fue interpretado por los chascones como un logro en sintonía histórica con las lecciones tomicistas de la "unidad social y política del pueblo", referente obligado de su memoria política. Sin embargo, quien encabezó el proceso fue Patricio Aylwin, líder indiscutido de los guatones, y no un referente del progresismo como Gabriel Valdés. La conclusión de "perdimos el candidato, pero ganamos la tesis de unidad de la centroizquierda", articula un relato generacional en tanto éxito: éxito en que se logró que la DC fuera oposición activa, éxito en que la DC se sumara a las movilizaciones contra la dictadura, éxito en que del trabajo conjunto de los chascones con la izquierda nació la Concertación. Las implicancias de la permanencia de la Constitución y los enclaves autoritarios que trajo el tipo de transición son interpretados en el relato chascón como efectos no deseados, pero no hay acá un duelo amargo por el modo en que se dio la transición y que sí se encuentra en algunos relatos testimoniales de la izquierda concertacionista. ${ }^{82}$ En general, el camino virtuoso de "reencuentro de los demócratas" y sus logros en el terreno (o la medida) de "lo posible", tiende a ser predominante en el relato generacional mediante el que los chascones se leen a sí mismos en la historia.

2.- Lo que definió a los chascones fue un posicionamiento fundamentalmente político estratégico para enfrentar la dictadura y no un proyecto específico de sociedad. No porque esto último no estuviera presente, sino porque durante la dictadura hubo en la DC una crítica técnica al modelo neoliberal, compartida por todos los sectores y que se anclaba en las nociones desarrollistas que este partido traía desde antes del golpe. Y aunque los chascones tuvieron en su discurso referencias al ideario socialista comunitario y de vía no capitalista de desarrollo (en su discurso de obtención de la presidencia de la FECH, Ljubetic

electoral binominal y sus efectos de sobrerrepresentación de la derecha, también fue considerado una herencia autoritaria condicionante de la política en posdictadura.

82 Muñoz Tamayo, Militancia, facciones... op cit, 2017. 
apuntaba a dejar atrás "las injusticias, la desigualdad y el capitalismo“"83), no fueron estos los temas que marcaron los principales deslindes con "los guatones". Por otro lado, hacia los años de transición no hubo tampoco un relato generacional chascón que relevara percepciones relativas a la aceptación y mantención de las bases de un modelo de desarrollo neoliberal que en principio se había criticado. Es decir, aunque cada militante pudo tener sus opiniones al respecto, no hubo un relato unificado asociado a un nosotros generacional chascón que diera continuidad a una identidad propia y distintiva.

3.- Si la posición político-estratégica para enfrentar el régimen estuvo al centro de la distinción entre corrientes DC durante dictadura, no hubo, con posterioridad, algo similar que determinara un clivaje potente desde donde se articularan subgrupos partidarios visibles y organizados, como lo habían sido los chascones y guatones en la JDC. Si bien podemos hablar de cierta permanencia de subagrupaciones partidarias, estas no tuvieron la organicidad, la visibilidad, permanencia ni tampoco la consistencia discursiva que tuvieron los subgrupos de chascones y guatones durante la dictadura.

4.- Nuestra impresión preliminar es que los subgrupos partidarios DC durante la posdictadura fueron de naturaleza mucho más coyuntural que lo que existió en dictadura. Lo que hubo en esa materia fue determinado más por matices tácticos, afinidades personales y cuestiones pragmáticas e instrumentales relativas a la distribución y organización del poder, que por clivajes de tipo político estratégico o político doctrinario. ${ }^{84}$ En eso, hubo resabios de identidad chascona que se aliaron coyunturalmente con diferentes grupos, incluyendo con otrora "guatones" (como una coyuntural alianza de guatones y chascones que se conoció como "la guacha").

5.- En el relato generacional chascón se asume la dispersión de la propia identidad como subgrupo o tendencia a partir de los años 90 . Se tiende sí a otorgar mayor continuidad, consistencia y efectividad a lo que habían sido los guatones, pero no tanto como sector con determinada tesis política, sino que fundamentalmente como grupo articulador y organizador del poder interno en la DC.

En definitiva, la transición evidencia los cambios que se dan en el propio campo de la política y que afectan transversalmente a los partidos políticos insertos en el sistema de representación democrática: a) la aceptación de las bases del modelo neoliberal, determinada por las restricciones autoritarias de la institucionalidad política (enclaves autoritarios) y sus efectos en la prácticas parlamentarias (política de los consensos), sitúa a los discursos en el campo de las correcciones técnicas y no de las discusiones relativas a transformaciones estructurales y modelos alternativos; b) esta tecnificación y, en cierta medida, desideologización de la política, interviene en que los deslindes entre subgrupos circunstanciales o referencias identitarias relativas a corrientes y líderes (ex chascones, o "la máquina” guatona o "gutista” en torno a Gutenberg Martínez), se relacionen más con la política como administración, distribución y organización de poder, que con la política

\footnotetext{
83 'Esta generación quiere ser protagonista de esa mayoría por los cambios que es lo único que asegurará que el Chile de mañana deje atrás las injusticias, la desigualdad, el capitalismo.. Yerko Ljubetic, Discurso de constitución de la FECH... op cit 160

84 Bernardo Navarrete, “Un centro excéntrico. Cambio y continuidad en la Democracia Cristiana 1957 - 2005“, Política, volumen 45, Universidad de Chile, Santiago, pp 137.
} 
como enfrentamiento programático e ideológico. ${ }^{85}$ En ese sentido, si bien lo chascón persiste como referencia de identidad, se acaba definitivamente en 1990 como subgrupo cohesionado de orientación política y estratégica.

En la memoria generacional quedó sí la marca vivencial de la rebeldía ante una tiranía, y también de la rebeldía ante el propio partido pues, aunque nunca rompieron con este último, propusieron constantemente nociones de autonomía generacional y sectorial que "chasconearon" los límites de la disciplina interna. Para los jóvenes chascones, la democracia de 1990 fue su marca de adultez. Entraron a la adultez al tiempo que el país entraba a la nueva democracia con todas sus restricciones y llamados a atender los límites de lo posible y las lecciones de gobernabilidad. En este contexto, los vientos de pragmatismo parecieron ser óptimos para la reputada habilidad guatona en la administración del poder y no tanto para la rebeldía chascona y su llamado de unidad en la base. Pero esa es otra historia. Los jóvenes DC chascones ya habían dejado su huella.

\section{Bibliografía citada.} 1998.

- Aylwin, Patricio. El reencuentro de los demócratas, Santiago, Ediciones Grupo Zeta,

-Boeninger, Edgardo. Gobernabilidad, lecciones de la experiencia, Santiago, Uqbar, 2014.

-Brodsky, Ricardo y Pizarro, Ramiro. La constitución del movimiento estudiantil como proceso de aprendizaje político. En Agurto Irene, Canales Manuel, De la Maza Gonzalo, Juventud chilena. Razones y subversiones, 1985 Santiago, Eco, Folico, Sepade.

-Ricardo Brodsky compilador, Conversaciones con la FECH, Santiago, SESOC, 1988.

-Corvalán Márquez, Luis. Del anticapitalismo al neoliberalismo en Chile, Santiago, Editorial Sudamericana, 2001.

-Donoso, Jorge y Dunlop, Grace. Los 13 del 13. Los DC contra el golpe, Santiago, Ril, 2013. -García Monge, Diego; Isla, José; Toro, Pablo. Los muchachos de antes. Historia de la FECH 1973 - 1988, Santiago, Universidad Alberto Hurtado, 2006.

- Grayson, George. El Partido demócrata Cristiano Chileno, Buenos Aires, Francisco de Aguirre, 1968.

-Hormazábal, Ricardo. La Democracia Cristiana y el gobierno de Allende, Santiago, Copygraph, 2014

-Moulián, Tomás. Fracturas. De Pedro Aguirre Cerda a Salvador Allende (1938-1973), Santiago, Lom, 2006.

-Moyano, Cristina. MAPU o la seducción del poder y la juventud, Santiago, Ediciones UAH, 2009.

-Muñoz Tamayo, Víctor. Generaciones. Juventud universitaria e izquierdas politicas en Chile y México (Universidad de Chile-UNAM 1984-2006), Santiago, LOM, 2011.

-Muñoz Tamayo, Víctor. ACU Rescatando el asombro. Historia de la Agrupación Cultural Universitaria, Santiago, Calabaza del Diablo, 2006.

\footnotetext{
85 Para el estudio de un fenómeno similar al interior del Partido Socialista, ver: Víctor Muñoz Tamayo, “El Partido Socialista de Chile y la presente cultura de facciones. Un enfoque histórico generacional (1973 - 2015)", Izquierdas, número 26, Santiago, USACH - IDEA, 2016.
} 
-Muñoz Tamayo, Víctor. "Militancia, facciones y juventud en el Partido Socialista Almeyda. (1979-1990) “, Revista Izquierdas 37, USACH IDEA, Santiago, 2017.

-Muñoz Tamayo, Víctor. "El Partido Socialista de Chile y la presente cultura de facciones. Un enfoque histórico generacional (1973 - 2015)", Izquierdas, número 26, Santiago, USACH - IDEA, 2016.

-Navarrete, Bernardo. "Un centro excéntrico. Cambio y continuidad en la Democracia Cristiana 1957 - 2005“, Política, volumen 45, Universidad de Chile, Santiago.

-Ortega, Eugenio y Moreno, Carolina, compiladores, ¿La concertación desconcertada? Reflexiones sobre su historia y su futuro, Santiago, Lom, 2002.

-Rojas Flores, Jorge. "Los estudiantes secundarios durante la Unidad Popular, 1970 1973“', Historia, número 42, PUC, Santiago, 2009.

-Sartori, Giovanni. Partidos y sistemas de partidos, Madrid, Alianza, 2005.

-Velasco, Belisario. Esta historia es mi historia. Catalonia, Santiago 2018. Página 221.

Documentos partidarios y de organizaciones.

- “Acuerdo del Consejo Nacional del Partido Demócrata Cristiano para la constitución de una Comisión Política Técnica para estudiar y proponer una "vía no capitalista de desarrollo“, Santiago, 6 de abril de 1967, Archivo Patricio Aylwin.

-. Jacques Chonchol, Tomás Reyes, Luis Maira, Vicente Sota, Julio Silva, Carlos Massad, Pedro Felipe Ramírez, Documento de trabajo para la Junta Nacional del PDC *Proposiciones para una acción política en el período 1967 - 70 de una vía no capitalista de desarrollo“, Santiago, Julio de 1967, Archivo Patricio Aylwin.

-. "Carta de Patricio Aylwin a los miembros de la Junta Nacional del Partido Demócrata Cristiano, con observaciones al informe político técnico de una vía no capitalista de desarrollo“, Santiago, 10 de octubre de 1967, Archivo Patricio Aylwin.

.- Renán Fuentealba, “Resumen del Informe del Senador Renán Fuentealba Presidente Nacional del PDC al Consejo Ampliado“, Santiago, 18 de marzo de 1972, Archivo Patricio Aylwin.

.- Gabriel Valdés, “Carta de Gabriel Valdés a Patricio Aylwin, Presidente Nacional del Partido Demócrata Cristiano, sobre la posición que ha tenido la Directiva Nacional en su relación con la Junta Militar", 27 de febrero de 1974, Archivo Patricio Aylwin.

.- Bernardo Leighton, Renán Fuentealba, Claudio Huepe, Radomiro Tomic y Ricardo Hormazábal, "Carta a Patricio Aylwin, presidente de la Democracia Cristiana”, 7 de abril de 1975, Archivo Patricio Aylwin.

.- Tomás Reyes, "Nuestra fuerza política y social al servicio de la recuperación democrática", enero de 1977, Archivo Patricio Aylwin.

- Andres Zaldivar, "Documento político presentado al Plenario del PDC", diciembre de 1976, Archivo Patricio Aylwin.

.- Acta de fundación de CODEJU, 8 de febrero de 1979. En: Guillermo Yunge, “Derechos Humanos, Derechos Juveniles: La Comisión Nacional Pro-derechos Juveniles de Chile CODEJU*, Cuadernos ESIN, Instituto para un nuevo Chile, Santiago, 1980. Biblioteca Nacional. 
.- Eduardo Frei, “'Discurso de Eduardo Frei pronunciado el 27 de agosto de 1980 en el Teatro Caupolícán", Documentación sobre observaciones y alternativas al plebiscito, Archivo Patricio Aylwin.

Listado de entrevistados.

\begin{tabular}{|c|c|c|}
\hline Nombre & $\begin{array}{l}\text { Año de } \\
\text { nacimiento. }\end{array}$ & Trayectoria en período estudiado. \\
\hline 1.- Juan Claudio Reyes. & 1955 & $\begin{array}{l}\text { Dirigente enseñanza media durante Unidad } \\
\text { Popular. Vicepresidente FESES 1972. Dirigente } \\
\text { estudiantil Universidad de Chile, estudiante de } \\
\text { sociología. Presidente del Comité Reorganizador } \\
\text { del Movimiento Estudiantil CORREME. }\end{array}$ \\
\hline 2.- Gustavo Rayo. & 1954. & $\begin{array}{l}\text { Dirigente enseñanza media durante Unidad } \\
\text { Popular. Dirigente estudiantil Universidad de } \\
\text { Chile en Escuela de Ciencias Políticas y } \\
\text { Administrativas. Presidente CODEJU 1979. }\end{array}$ \\
\hline 3.- Rodolfo Fortunatti. & 1955 & $\begin{array}{l}\text { Dirigente enseñanza media durante Unidad } \\
\text { Popular. Dirigente estudiantil Universidad de } \\
\text { Chile, estudiante de sociología. }\end{array}$ \\
\hline 4. Yerko Ljubetic. & 1960 & $\begin{array}{l}\text { Dirigente estudiantil Universidad de Chile, } \\
\text { estudiante de Derecho. Presidente FECH } 1984 \text { - } \\
\text { 1985. }\end{array}$ \\
\hline 5.- Humberto Burotto. & 1961 & $\begin{array}{l}\text { Dirigente estudiantil Universidad de Chile, } \\
\text { estudiante de sociología. Presidente FECH } 1985 \text { - } \\
1986 .\end{array}$ \\
\hline 6. Cecilia Valdés. & 1967 & $\begin{array}{l}\text { Dirigente en comuna de Estación Central y en } \\
\text { Instituto Blas Cañas, estudiante de pedagogía en } \\
\text { educación física. }\end{array}$ \\
\hline 7.- José Antonio Sabat. & 1968 & $\begin{array}{l}\text { Dirigente enseñanza secundaria, comité Pro } \\
\text { FESES y FESES. }\end{array}$ \\
\hline 8.- Eduardo Zaffirio. & 1958 & $\begin{array}{l}\text { Dirigente estudiantil Universidad de Chile, } \\
\text { escuela de Derecho. Militante vinculado a } \\
\text { corriente conocida como "los iluminados". }\end{array}$ \\
\hline 9.- Ricardo Hormazábal. & 1946 & $\begin{array}{l}\text { Presidente JDC y parlamentario durante Unidad } \\
\text { Popular. Presidente JDC en dictadura hasta año } \\
1974 .\end{array}$ \\
\hline 10.- Andrés Palma. & 1955 & $\begin{array}{l}\text { Dirigente estudiantil de los colegios particulares } \\
\text { durante la Unidad Popular. Vicepresidente de la } \\
\text { Federación de Estudiantes de Colegios } \\
\text { Particulares de Chile. Dirigente DC Universidad } \\
\text { de Chile durante dictadura, en facultad de } \\
\text { economía. Presidente JDC en 1985. Empata con } \\
\text { Miguel Salazar en elecciones de directiva JDC en } \\
\text { 1984, se divide el período y Palma asume como } \\
\text { presidente desde } 1985 \text {. }\end{array}$ \\
\hline
\end{tabular}

